\title{
The evolution and patterning of male gametophyte development
}

Dieter Hackenberg* and David Twell*

Department of Genetics and Genome Biology, University of Leicester, University Road, Leicester LE1 7RH

*Authors for correspondance: Dieter Hackenberg (h253@le.ac.uk) and David Twell (twe@le.ac.uk)

Table of contents:

Abstract

1. The evolutionary history of the male gametophyte

1.1. The origins of spermatogenesis in green plants

1.2. The sporophyte was key for terrestrial plant evolution

1.3. Heterospory and the origin of microgametophytes

1.4. Adaptations of seed plant microgametophytes

2. Male germline development in angiosperms

2.1. Asymmetric division and cell fate determination

2.2. Cell cycle control and male gametophyte patterning

2.3. Transcriptional control of male gametophyte patterning

2.4. Chromatin remodelling in male gametophyte development

2.5. Communication between non-germ and germ cells

3. Molecular evolution of the male germline

3.1. Motile plant and animal sperm share common features

3.2. Gene expression in male germ cells

3.3. The evolution of transcription factors regulating male gametogenesis

4. Perspective

5. Acknowledgements 


\title{
6. References
}

Keywords: Sexual reproduction, male gametogenesis, gametes, sperm, pollen, flagella, transcription factors, chromatin, green algae, Arabidopsis thaliana, Marchantia polymorpha, Ginkgo biloba, molecular evolution

\begin{abstract}
The reproductive adaptations of land plants have played a key role in their terrestrial colonization and radiation. These encompass mechanisms used for the production, dispersal and union of gametes to support sexual reproduction. The production of small motile male gametes and larger immotile female gametes (oogamy) in specialized multicellular gametangia evolved in the charophyte algae, the closest extant relatives of land plants. Reliance on water and motile male gametes for sexual reproduction was retained by bryophytes and basal vascular plants, but was overcome in seed plants by the dispersal of pollen and the guided delivery of non-motile sperm to the female gametes. Here we discuss the evolutionary history of male gametogenesis in streptophytes (green plants) and the underlying developmental biology, including recent advances in bryophyte and angiosperm models. We conclude with a perspective on research trends that promise to deliver a deeper understanding of the evolutionary and developmental mechanisms of male gametogenesis in plants.
\end{abstract}

\section{The evolutionary history of the male gametophyte}

\subsection{The origins of spermatogenesis in green plants}

The ancestral mode of sexual reproduction in plants is isogamy (gametes of similar size and morphology) and is described in basal chlorophyte and charophyte algae. Oogamy (sperm and egg mating systems) evolved independently in both algal lineages, and the transition from isogamy to oogamy is associated with increasing complexity and colonisation (reviewed in Mori et al., 2015; Umen, 2014). 
The Volvocine algae have been developed as a model for the evolution of reproductive traits among chlorophytes. The unicellular species Chlamydomonas reinhardtii is isogamous and one of the most basal species (Nozaki et al., 2000), whereas colonial and multicellular genera can be isogamous, anisogamous or oogamous (Mori et al., 2015). The differentiation of plus and minus gametes in C. reinhardtii is determined by a $200-300 \mathrm{~kb}$ multigenic mating type (MT) locus. Gametes are $M T$-, if the MID (minus dominance) gene is present or $M T+$, if $M I D$ is absent (Ferris et al., 2002; Ferris \& Goodenough, 1994). MID encodes an RWP-RK domain transcription factor and acts as a master regulator of sexual differentiation (Ferris \& Goodenough, 1997). From its ancestral role as a mating-type factor in C. reinhardtii, MID has evolved to become a determinant of sperm and egg development in oogamous Volvox carteri (Geng et al., 2014). Although orthologs of MID are present in land plant genomes, their functions are currently unknown (Rövekamp et al., 2016).

In charophyte algae the phylogenetic transition from isogamy to anisogamy (Figure 1) and the genes responsible for sex determination remain unclear. With the exception of the unicellular isogamous Mesostigma viride, sexual reproduction in most charophyte lineages is unknown (Delwiche, 2016; McCourt et al., 2004; Mori et al., 2015) However, late divergent lineages, such as Charales and Coleochaetales, developed oogamous reproduction with bi-flagellated sperm (Renzaglia \& Garbary, 2001). The stoneworts of the genus Chara produce gametes in morphologically complex gametangia, known as globules (antheridia) (Figure 2A) or nucules (oogonia), that are speculated to be homologous to gametangia of basal land plants (Niklas \& Kutschera, 2009). Interestingly, the Zygnematales, an extant charophyte order sister to land plants (Wodniok et al., 2011), secondarily lost flagella and reproduce through isogamous conjugation (McCourt et al., 2004).

1.2 The sporophyte was key for terrestrial plant evolution

Charophyte algae developed a haplontic life cycle, in which the haploid stage is multicellular and the only diploid stage is the unicellular zygote (Shaw et al., 2011). The haplodiplontic life 
cycle, which involves the alternation of multicellular haploid and diploid generations, evolved with the colonization of terrestrial habitats (Figure 1). This transition requires a delay of meiosis and the intercalation of mitotic cell divisions; the resulting multicellular sporophyte thereby amplifying haploid spore production from each zygote. The limited capacity of charophyte algae for dispersal via motile sperm, therefore gave way to terrestrial colonisation via dissemination of durable spores shed by increasingly complex and dominant sporophytes (reviewed in Niklas \& Kutschera, 2009).

The production of desiccation-tolerant spores by elevated sporophytes promoted aerial dispersal of gametophytes (Strother et al., 1996; Wellman, 2010). This key innovation was enabled by synthesis of the resistant biopolymer sporopollenin in spore walls (Niklas \& Kutschera, 2009). The ability to produce sporopollenin is shared by chlorophyte and charophyte algae (Brooks \& Shaw, 1978) and is considered pre-adaptive for terrestrial colonization (Wallace et al., 2011). The homology between 'lower' plant spores and the pollen of seed plants is bolstered by the presence of homologues of pollen wall associated genes in moss (Wallace et al., 2011). Further, the GAMYB family of transcription factors, which have been shown to regulate sporopollenin biosynthesis genes, are required for the formation of functional spores in moss and for pollen wall formation in angiosperms (Aya et al., 2011, 2009).

The molecular control of the haploid-to-diploid transition seems to share common ancestry in green algae and land plants. In C. reinhardtii, plus and minus gametes express either BEL1LIKE (BELL) or KNOTTED1-LIKE HOMEOBOX (KNOX) class homeodomain proteins, respectively. After gamete fusion, these proteins heterodimerize to initiate zygote development and meiosis (Lee et al., 2008). Similarly, KNOX/BELL heterodimers pattern sporophyte development in moss (Physcomitrella patens) and in flowering plants, but are neither functional nor expressed during the gametophytic phase (Hay \& Tsiantis, 2010; Keiko et al., 2008). While antagonistic roles are proposed for the duplicated KNOX1 and KNOX2 gene classes in sporophytic development in angiosperms, KNOX2 genes actively represses 
the gametophytic body plan in sporophytes of P. patens (Furumizu et al., 2015; Sakakibara et al., 2013).

In bryophytes, the gametophytic phase is dominant and the mature gametophyte is either a thallus or a leafy shoot with indeterminate growth (Ligrone et al., 2012). Male (antheridia) and female (archegonia) gametangia are commonly produced by differentiation of the growing tip of the shoot (gametophore), producing either sperm or eggs cells by mitotic division. In the liverwort Marchantia polymorpha, antheridia consist of spermatogenous cells surrounded by a single layer of sterile jacket cells (Figure 2B; Durand, 1908; Shimamura, 2016). The spermatogenous cells undergo proliferative mitotic divisions, eventually dividing diagonally to form a pair of triangular sperm cells (Durand, 1908). Similar to their charophycean ancestors, the bryophytes (liverworts, hornworts and mosses) release motile sperm into environmental water (Figure 3A). During spermatogenesis the cells undergo complex morphological changes, including extreme cytoplasmic reduction, nuclear condensation, and flagella assembly (see section 3.1; Renzaglia \& Garbary, 2001).

[insert Figure 1 here]

Figure 1. Evolution of the gametophyte and sporophyte in the land plant lineage. The upper panel illustrates the trend from a dominant haploid gametophyte to that of the diploid sporophyte. Charophyte algae have a haplontic life cycle and possess a multicellular gametophyte, but only the zygote is diploid. The haplodiplontic life cycle and multicellular sporophyte evolved in bryophytes, while complex sporophytes are dominant in vascular plants (eg. monilophytes and spermatophytes). In spermatophytes (ie. gymnosperms and angiosperms), the gametophyte is reduced to a few cells and is entirely dependent on the sporophyte. The lower panel shows a cladogram of streptophyte (green plant) taxa indicating their estimated times of divergence and associated reproductive adaptations. Geologic eras are colored; Cenozoic (white), Mesozoic (blue), Paleozoic (green), Neoproterozoic (brown). 
The increase in size and complexity of the sporophytes of vascular plants is matched by corresponding reductions in their gametophytes (Figure 1). Basal extant lycophytes and monilophytes produce free-living exosporic gametophytes (prothallia) with flattened thalloid anatomy, or subterranean tuber-like structures (Ligrone et al., 2012). These taxa retain an oogamous life style and prothallia produce gametes in separate male and female gametangia, similar to those of bryophytes.

The spores of extant bryophytes and basal vascular plants are uniform in size, a condition known as homospory. Heterospory, defined as the production of smaller male microspores and larger female megaspores, arose independently in all major vascular plant lineages (lycophytes, monilophytes and spermatophytes) and is considered a key innovation for terrestrial colonization (Bateman \& DiMichele, 1994; Petersen \& Burd, 2016). Endospory, the development of gametophytes within the spore wall, is tightly coupled to unisexuality and is proposed as an innovation that allowed the evolution of heterospory (Bateman \& DiMichele, 1994). The transition to endospory increased the influence of the diploid parent on gametogenesis, and allowed spore production and release to be synchronized with favourable environmental conditions.

The reduction of the gametophyte and transition to endospory is exemplified by comparison of the male gametophytes of the dioicous liverwort $M$. polymorpha and the heterosporous water fern Marsilea vestita. In M. polymorpha, antheridial initial cells arise from epidermal cells of the receptacle on a reproductive branch called the antheridiophiore (Durand, 1908). Initial cells divide several times prior to a formative asymmetric division, which gives rise to a spermatogenous mother cell and a sterile jacket cell. Each mother cell undergoes multiple rounds of division to produce several thousand spermatozoids within each antheridium (Figure 2B). In contrast, microspores of $M$. vestita complete one asymmetric and one symmetric division before spermatogenous cells are produced by a formative asymmetric division. The spermatogenous cells undergo four rounds of symmetric division to produce a total of 32 spermatozoids within each microspore (Figure 2C; Sharp, 1914). 
This trend towards fewer antheridial divisions prior to spermatogenesis culminates in the highly reduced male (micro)gametophytes of seed plants (Figure 2D - F). In gymnosperms, microspores undergo asymmetric cell divisions to produce one or more prothallial cells, prior to segregation of a spermatogenous cell lineage (Figure 2D and E). Reduction of the microgametophyte is most extreme in angiosperms, which require only two cell divisions to produce two non-motile sperm cells from the microspore (Figure 2F). This indicates that the asymmetric cell divisions which produce one or more prothallial cells in gymnosperms are absent, and the germline is directly segregated by asymmetric division of the microspore (see Rudall \& Bateman 2007).

[insert Figure 2 here]

Figure 2: Overview of cell division patterns during male gametogenesis in representative streptophytes. Sperm cell lineage nuclei are green; primary microspore nucleus (C to F) is blue; basal antheridial/stalk ( $\mathrm{A}$ and $\mathrm{B}$ ) and prothallial cell nuclei (C to $\mathrm{E}$ ) are purple; nonreproductive cell nuclei, derived from the male reproductive lineage, are orange. (A) Chara spp. globule (antheridium) development starts with division of an apical initial cell to form apical (green) and basal (purple) antheridial cells. Apical cells form inner primary capitular cells (green) and outer shield cells (orange). Capitular cells give rise to antheridial filament initial cells (green). Antheridial filament cells divide and then differentiate to form biflagellate spermatozoids (green), whereas filament initial cells become non-reproductive (orange). (B) Marchantia polymorpha antheridia are formed by division of an antheridial initial to form outer primary antheridial cells (green) and inner stalk cells (purple). Primary antheridial cells divide asymmetrically to generate sterile jacket cells (orange) and spermatogenous cells (green), which divide repeatedly. Each spermatogenous mother cell divides diagonally before differentiating into bi-flagellated spermatozoids. (C) Marsilea vestita microspores (blue) divide asymmetrically to form an antheridial initial cell (green) and a prothallial cell (purple), which no longer divides. The antheridal initial divides symmetrically and both daughter cells (green) complete three rounds of asymmetric division to produce three sterile jacket cells 
(orange) and a primary spermatogenous cell (green). Each spermatogenous cell divides to form four spermatocyte mother cells (green), which divide into eight spermatocytes. These cells divide to form 16 spermatids which differentiate into multiflagellated spermatozoids. (D) Gingko biloba microspores (blue) divide twice to form one antheridial (green) cell and two prothallial (purple) cell that do not divide further. The antheridial cell forms the generative cell (green) and tube cell (orange) by asymmetric division. The generative cell divides again to form a sterile stalk cell (orange) and a body cell (green), which divides and differentiates to produce mutliflagellated sperm (see Figure 3C). (E) Gnetum gnemon microspores (blue) divide asymmetrically to form an antheridial cell (green) and a single prothallial cell (purple). The antheridial cell undergoes asymmetric division to produce generative cell (green) and a tube cell (orange). The generative cell divides to form two non-motile sperm nuclei. (F) Arabidopsis thaliana microspores (blue) divide asymmetrically to form the generative cell (green) and the vegetative cell (orange). The generative cell undergoes a second symmetric division to form two non-motile two sperm cells (green). The figure is adapted and redrawn from (A), Kwiatkowska et al. (2002), (B), Durand (1908), (C), Tsai et al., (2004), and (E-F), Rudall \& Bateman (2007).

\subsection{Adaptations of seed plant microgametophytes}

The development of male and female gametophytes of seed plants (spermatophytes) take place in micro- and megasporangia formed on modified leaves (sporophylls) in cones or in flowers. In contrast to most free-sporing plants, immature microgametophytes of seed plants are dispersed as desiccation-tolerant pollen. The evolution of pollen is a milestone in the adaptation of seed plants to terrestrial habitats. By contrast, the endosporic female megagametophyte remains partially or completely enclosed by sporophytic tissues, the nucellus and integument (see Gasser \& Skinner, this issue; Erbasol Serbes et al., this issue). Thus, sperm cells must either swim to the megagametophyte enclosed by the integument or be delivered via the pollen tube. 
With some important exceptions, extant gymnosperms and angiosperms transitioned from zooidogamy (swimming sperm) to siphonogamy (conduction of non-motile sperm via a pollen tube) (Friedman, 1993; Gifford \& Foster, 1989). In cycads and in Ginkgo biloba, pollen tubes have a primarily haustorial role to support the development of large flagellated spermatozoids (Figure 3C; Friedman \& Gifford, 1997). Flagellated spermatozoids of these taxa develop slowly after pollination and are released proximally into a pollen chamber. Spermatozoids subsequently migrate to the egg cells at the micropylar end of the ovule (Rudall \& Bateman, 2007).

In gymnosperms, pollen reception must be relatively near to the egg as pollen tubes are relatively slow growing. Furthermore, the time between pollination and fertilisation can take days to months. In angiosperms, pollen tube growth is significantly faster, shortening the progamic phase to hours or minutes, thereby facilitating the evolution of rapid reproductive cycles (Williams, 2008). The evolution of fast-growing angiosperm pollen tubes is linked with modifications to pollen tube walls, including callose-reinforced secondary tube walls, callose plugs, and extensible pectin tips. Rapid pollen tube growth and longer-distance growth are considered to be key features enabling carpel diversification and the multiplicity of flower and fruit form (Williams, 2008).

Double fertilization senu stricto is a synapomorphy (derived trait shared by two or more taxa) of angiosperms and occurs following the delivery of a pair of sperm cells to the ovule, resulting in the formation of embryo and endosperm. In the Gnetales however, a modified form of this process produces a supernumerary embryo (Carmichael \& Friedman, 1995; Friedman, 1998, 1990). Double fertilisation enhances the fitness of the embryo, but also contributes to maternal fitness, as resources are only committed to the ovule after the egg and central cell have been fertilized. The two sperms cells can be functionally equivalent as demonstrated for Arabidopsis thaliana (Hamamura et al., 2011; Ingouff et al., 2009; Kong et al., 2015), and the majority of species show an equal distribution of DNA-containing 
organelles among the two sperm (Saito et al., 2002). However, dimorphic sperm, which show preferential fertilization and differing gene expression profiles, are described for Plumbago zeylanica (Gou et al., 2009; Russell, 1985).

An important life history trait for adaptation to particular ecological niches is the length of the life cycle. In time-limited habitats, short lifecycles are commonly associated with an annual habit, shorter bud development time, and reduced flower longevity (i.e. reduced time between flower maturation and fertilization) among other reproductive traits (Snell \& Aarssen, 2005). Although gymnosperms disperse sexually immature pollen (Fernando et al., 2010; Friedman, 1999), angiosperms have evolved mechanisms to minimize the length of the reproductive phase. This involves the advancement of pollen maturity before dispersal. In about $70 \%$ of angiosperms, pollen is dispersed in a bicellular state and division of the generative cell takes place during pollen tube growth. The remainder undergo precocious division of the generative cell and disperse tricellular pollen containing two sperm cells (Brewbaker, 1967; Williams et al., 2014). Tricellular pollen is considered advanced and is associated with shorter reproductive cycles, reduced longevity, rapid germination, and faster pollen tube growth (Brewbaker, 1967; Rowe et al., 2012; Williams, 2012). Although less common, tricellularity does not appear to be irreversible and multiple instances of secondary shifts from tricellular to bicellular pollen are postulated (Williams et al., 2014). In rare cases, as in Annona cherimola, a mixture of bicellular and tricellular pollen is dispersed and the onset of generative cell division is advanced by increases in air temperature (Lora et al., 2009). This may be adaptive, potentially providing plasticity in response to dispersal conditions.

In summary, the advanced microgametophytes of seed plants evolved from their embryophyte ancestors by the acquisition of several key features. These are, endospory and an extreme reduction of mitotic cell divisions prior to segregation of the male germline senu stricto, increased sporophytic dependency, and adaptation to a siphonogamous gamete delivery 
system involving the loss of gamete motility. Subsequent diversification in the onset and pace of gametogenesis has enabled the microgametophytes of angiosperms to adapt to a diversity of niches.

[insert Figure 3 here]

Figure 3: Micrographs of motile spermatozoids of plants. Scanning electron micrographs of (A), bi-flagellated spermatozoid of the liverwort Conocephalum conicum (reprinted with permission from Renzaglia \& Garbary, 2001), (B), multi-flagellated spermatozoid of the leptosporangiate fern Ceratopteris richardii (reprinted with permission from Lopez-Smith \& Renzaglia, 2008) and (C), light micrograph of motile sperm of the gymnosperm Ginkgo biloba (reprinted with permission from Suzuki et al., 2000). Scale bars, (A, B), $2.0 \mu \mathrm{m},(\mathrm{C})$, $80 \mu \mathrm{m}$.

\section{Male germline development in angiosperms}

Molecular and genetic studies of male germline development documented in earlier reviews are dominated by those of angiosperms (Berger \& Twell, 2011; Russell \& Jones, 2015; Twell, 2011). Other recent reviews focus on omics (Fíla et al., 2017; Rutley \& Twell, 2015), chromatin remodelling (Borg \& Berger, 2015), post-transcriptional processes (Guan et al., 2013; Hafidh et al., 2016; Michard et al., 2017), or wider aspects of reproductive cell lineages (Schmidt et al., 2015). Here we focus on regulatory aspects of male gametogenesis including comparative studies and advances in pre-angiosperm models. We discuss the role of asymmetric division and cell cycle control in patterning, and the roles and regulation of transcription factors in cell specification; we also highlight chromatin remodelling and communication between germline and non-germ cells.

\subsection{Asymmetric microspore division and cell fate determination}

Studies in angiosperms have shown that asymmetric microspore division is formative and essential for the establishment of germ cell fate. The induction of symmetric microspore divisions by environmental or chemical agents, such as the microtubule poison colchicine, 
results in daughter cells with vegetative cell-like nuclei (Tanaka \& Ito, 1980; Terasaka \& Niitsu, 1987) and vegetative cell marker expression (Eady et al., 1995). Mutations which disturb microspore polarity or division have also been informative. In gemini pollen 1 (gem1) mutants of $A$. thaliana, microspores can undergo equal divisions and both daughter cells adopt vegetative cell fate, similar to the products of chemically-induced symmetric divisions (Park et al., 1998). The pollen phenotypes of geml result from loss of microspore polarity and cytokinesis defects, arising from mutations affecting the MICROTUBULE-ASSOCIATED PROTEIN215 (MAP215)-family protein MICROTUBULE ORGANIZATION1 (MOR1)/GEM1 (Figure 4; Park et al., 1998; Twell et al., 2002; Whittington et al., 2001). Vegetative cell fate is also adopted in single-celled pollen resulting from colchicine treatment of tobacco microspores (Eady et al., 1995), or from cytokinesis defects (Park et al., 1998; Twell et al., 1998). Recent studies of additional single-celled pollen mutants confirm vegetative cell fate as the default programme, and show that pollen tubes are guided and discharge their contents in the absence of gametes (Glöckle et al., 2018; Zhang et al., 2017).

A novel class of cytokinesis mutants, which fail to compartmentalize newly-formed vegetative and generative cell nuclei, provides insight into the mechanisms underlying germ cell fate determination. Microspores polarize in two-in-one (tio) (Oh et al., 2005) and Kinesin$12 A / B$ double mutants (Lee et al., 2007), but failure of cytokinesis results in binucleate pollen unable to differentiate sperm. The TIO Fused kinase and KINESIN-12 interact to form a signalling module (Figure 4), which is thought to act via the canonical NACK-PQR MITOGEN-ACTIVATED PROTEIN KINASE (MAPK) pathway (Soyano et al., 2003) to regulate phragmoplast expansion (Oh et al., 2008, 2012). Collectively, mutants of this class form a presumptive generative cell nucleus, but this fails to divide and nuclear chromatin is gradually dispersed, consistent with the default vegetative cell fate. Thus, germ cell fate cannot be established without confinement of daughter nuclei to unequal compartments. 
The correct developmental timing of mitosis and spindle orientation are essential requirements for asymmetric microspore division and cell fate determination. Mutations in SIDECAR POLLEN (SCP) disturb the orientation of microspore division (Figure 4), resulting in tricellular pollen containing an extra vegetative cell (Chen \& McCormick, 1996). Defects arise following delayed microspore division, indicating close coupling of cell cycle progression and spindle orientation (Oh et al., 2010). SCP is a microspore-specific LATERAL ORGAN BOUNDARIES-DOMAIN/ASYMMETRIC LEAVES2-LIKE (LBD/ASL) domain family protein, whose expression overlaps with that of other family members in developing pollen. SCP (LBD27) and LBD10 form nuclear-localised heterodimers and act synergistically to control pollen development (Kim et al., 2015). Thus, combinatorial interactions among LBD proteins are thought to be important for their roles in the male gametophyte (Kim et al., 2016).

In summary, the asymmetric division of angiosperm microspores is critical for the formation and specification of the male germline sensu stricto. Studies of a variety of mutants strengthen the hypothesis that germ cell fate is specified by the segregation and confinement of yet unknown determinants by a new cell wall (Twell, 2011; Twell et al., 1998).

\subsection{Cell cycle control and male gametophyte patterning}

Correct patterning of the male gametophyte requires differential control of the cell cycle in vegetative and generative cells. Failure of generative cell division, resulting in bicellular pollen with a single germ cell, has been described for several $A$. thaliana mutants. Among the genes affected are those encoding the core cell cycle machinery, like the A-type cyclindependent kinase (CDK), CDKA;1. In $c d k a ; 1$ mutants, S-phase is retarded and generative cells are only able to divide during pollen tube growth (Figure 4; Aw et al., 2010; Iwakawa et al., 2006; Nowack et al., 2005). CDKA;1 activity and cell cycle progression are maintained in the generative cell by the proteasome-dependent degradation of the KIP-RELATED PROTEIN (KRP) CDK inhibitors. KRPs are targeted for degradation by the $\mathrm{SCF}^{\mathrm{FBL} 17}$ (SKP- 
CULLIN-F-BOX) E3 ubiquitin protein ligase complex, which contains the F-box protein FBL17 (Figure 4; Kim et al., 2008). In fbll7 mutants, generative cells fail to divide as CDK inhibitors are not degraded (Gusti et al., 2009; Kim et al., 2008). The transient expression of FBL17 only in the generative cell soon after microspore division is thought to license proliferation of the germline, while KRPs are maintained in the vegetative cell (Figure 4; Kim et al., 2008). Importantly, the FBL17-KRPs-CDKA;1 cascade is linked to the RBR1-E2F pathway to form a general G1/S regulatory module that also functions in microspores of $A$. thaliana, but is likely to control entry into S-phase in all cells (Zhao et al., 2012).

Patterning of angiosperm microgametophytes is also determined by the retinoblastoma $(R b)$ E2F pathway, which regulates cell cycle progression in a variety of organisms (Figure 4; Gutzat et al., 2012; Harbour \& Dean, 2000). $R b$ function is dependent on its phosphorylation by $\mathrm{CDK}$ in late G1-phase. This alleviates $\mathrm{Rb}$-mediated repression of the E2F/DP family transcription factors which commit cells to S-phase (Weinberg, 1995). The A. thaliana $R b$ homologue RETINOBLASTOMA-RELATED1 (RBRl) is highly expressed in the vegetative cell along with $K R P$ genes encoding CDK inhibitors (Kim et al., 2008). Loss of $R B R 1$ results in hyperproliferation of the vegetative cell and to a lesser extent the generative cell (Chen et al., 2009; Johnston et al., 2008). Hyperproliferation in $\operatorname{rbrl}$ mutants is caused by $C D K A ; 1$ activity, since introduction of a $c d k a ; 1$ mutant allele supresses this phenotype in rbrl pollen (Chen et al., 2009). Interestingly, cell fate is incorrectly specified in a fraction of rbrl vegetative cells, but this phenotype is completely reversed in the absence of $C D K A ; 1$. These findings point to $R B R 1$ primarily controlling cell cycle progression, while having a secondary impact on cell fate commitment. This places RBR1-mediated repression of E2F/DP downstream of KRP-dependent inhibition of CDKA;1, with both mechanisms enforcing cellcycle exit, thereby restricting cell fate (Figure 4). In addition, E2F and RBR1 can both bind to the FBL17 promoter and are thought act antagonistically to stimulate or repress FBL17 expression, respectively (Zhao et al., 2012). Thus, increased RBR1 protein in the vegetative 
cell would result in less FBL17 and reduced degradation of KRPs, thereby reinforcing cell vegetative cell cycle exit.

\subsection{Transcriptional control of male gametophyte patterning}

Regulators that integrate the control of cell division and germline fate

The male germline-specific R2R3 Myb-domain protein DUO POLLEN1 (DUO1) was the first transcription factor to be identified with a role in generative cell division (Rotman et al., 2005). Mutant generative cells of $d u o 1$ pollen complete S-phase, but fail to enter mitosis due to reduced accumulation of the mitotic cyclin, CYCB1;1 (Brownfield et al., 2009a; Durbarry et al., 2005). DUO1 also regulates a network of genes required for sperm cell differentiation (Borg et al., 2011; Brownfield et al., 2009a). Direct targets of DUO1 include genes encoding the sperm-egg adhesion protein, GAMETE EXPRESSED2 (GEX2) (Engel et al., 2005; Mori et al., 2014), and the sperm cell-surface fusogen, GENERATIVE CELLSPECIFIC1/HAPLESS2 (GCS1/HAP2) (Takahashi et al., 2017; von Besser et al., 2006). Thus, DUO1 has an integrative role, controlling G2 to M-phase transition and shaping the germline transcriptome to promote spermatogenesis (Borg et al., 2011; Brownfield et al., 2009a). DUO1 forms a regulatory module with two of its direct targets, the $\mathrm{C}_{2} \mathrm{H}_{2}$ zinc finger repressor protein encoding genes DUO1-ACTIVATED ZINC FINGER PROTEIN1 (DAZ1) and $D A Z 2$. Current data support a $D U O 1-D A Z 1 / 2$ network model in which the $D A Z 1 / 2$ node controls G2- to M-phase transition and DUO1-dependent gamete differentiation through a negative regulatory circuit involving physical interaction of DUO1 with the corepressor TOPLESS (TPL) (Figure 4; Borg et al., 2014).

The expression of a subset of germline genes under DUO1 control, including GCS1/HAP2 and GEX2, also requires the homeodomain-like protein DUO3 (Brownfield et al., 2009b). DUO1 and DUO3 have overlapping roles in gametogenesis, but unlike in duol mutants, generative cell division cannot be rescued by $C Y C B 1 ; 1$ expression in duo3 mutants. Moreover, DUO3 is expressed in sporophytic tissues and has an essential role in 
embryogenesis. DUO3 is a functionally conserved protein in land plants, as the A. thaliana duo3 mutant is rescued by the moss DUO3 orthologue (Brownfield et al., 2009b). The ancestry of DUO3 also extends to protein domains conserved with cell lineage regulators including GON-4 (GONADLESS-4) of Caenorhabditis elegans and vertebrate Gon41 (Gon4like), which are required for gonadogenesis (Liu et al., 2007; Williams et al., 2018) and haematopoeisis (Friedman et al., 2000) respectively. DUO3, in common with Gon4l, is proposed to act as a scaffold, enabling the assembly of distinct transcriptional complexes in restricted cell types (Brownfield et al., 2009b; Lu et al., 2011; Williams et al., 2018).

Regulation of DUO1 expression

The DUO1-DAZ1 regulatory module is an essential switch in angiosperm spermatogenesis. Strict spatial control of DUO1 is vital as ectopic expression results in vegetative growth defects or pollen cell death (Brownfield et al., 2009a; Palatnik et al., 2007). Initial efforts to understand this tight control, identified a 198 bp DUO1 promoter fragment sufficient for generative and sperm cell-specific transcription (Brownfield et al., 2009a). Phylogenomic studies have delimited important sequences in this region to an ordered cis-regulatory module (CRM), termed regulatory region of DUO1 (ROD1). ROD1 has a distinct architecture in eudicots; three DNGTGGV motifs are required to initiate germline expression and two YAACYGY motifs bound by DUO1, enhance expression in a positive feedback loop (Peters et al., 2017). ROD1 is functionally conserved in Medicago trunculata, but absent from preangiosperm $D U O 1$ promoters, indicating a shift in the transcriptional control of DUO1 in pollen after the divergence of gymnosperms and angiosperms 300-350 Mya (Peters et al., 2017).

The control of DUO1 expression is fine-tuned by several mechanisms. A negative feedback loop is thought to contribute to the developmental phasing of DUO1 and DAZ1/DAZ2 expression, involving the limitation of DUO1 accumulation in sperm by $D A Z 1 / D A Z 2$ (Figure4; Borg et al., 2014). A possible mechanism could involve miR159-mediated 
regulation, since the DUO1 transcript contains a functional miR159 binding site (Palatnik et al., 2007), and increased expression of DUO1 has been associated with reduced levels of the Anaphase Promoting Complex APC/C and miR159 (Zheng et al., 2011). There is also evidence for positive regulation of DUO1 by the pollen-specific AT-RICH INTERACTING DOMAIN1 (ARID1) protein, which binds to a promoter region upstream of ROD1 (Zheng et al., 2014).

In recent work, mutations in two distinct families of basic helix-loop-helix (bHLH) transcription factors were reported to cause profound defects in A. thaliana male gametogenesis. BONOBO1 (BNB1) and BNB2 are pollen-specific members of the bHLH subfamily VIIIa, which are redundantly required for generative cell specification (Yamaoka et al., 2018). DEFECTIVE REGION OF POLLEN1 (DROP1) and DROP2 are members of bHLH subfamily XI (Heim et al., 2003) that were previously shown to function in root hair elongation (Lin et al., 2015). In pollen of bnb1 bnb2 double mutants, generative cells are not engulfed by vegetative cells (Yamaoka et al., 2018), while generative cell nuclei disintegrate in drop1 drop2 pollen (Zhang et al., 2017). Generative cells fail to differentiate in both double mutants and sperm cell marker genes like DUO1 and GCS1/HAP2 (in drop1 drop2) or HISTONE THREE RELATED10 (HTR10) (in bnb1 bnb2) are not expressed (Yamaoka et al., 2018; Zhang et al., 2017). In conclusion, $B N B 1 / 2$ and $D R O P 1 / 2$ are required for early generative cell development and for germline differentiation, highlighting their potential as upstream regulators of the DUO1-DAZ1 module (Figure 4).

Regulators of pollen maturation that act in the vegetative cell

The MIKC* MADS-domain proteins are an ancient class of transcriptional regulators which play an essential role in pollen maturation and germination in angiosperms (Adamczyk and Fernandez, 2009; Liu et al., 2013; Verelst et al., 2007a, 2007b). Pollen-specific members of the MIKC* gene family in A. thaliana and Oryza sativa (rice) are restricted to the vegetative cell and form heterodimeric complexes (Liu et al., 2013; Verelst et al., 2007a). In A. thaliana, 
AtMIKC* complexes regulate pollen development by repressing early pollen genes and activating mature pollen genes. For example, the male gametophyte-specific transcription factor gene WRKY34 is upregulated, while MYB97 is downregulated in the absence of MIKC* complexes (Figure 4; Verelst et al., 2007b). Interestingly, MYB97 is a member of a sub-clade of S18 (GAMYB) R2R3 MYB proteins (MYB97, MYB101, MYB120), which act redundantly to promote the discharge of sperm from pollen tubes in the embryo sac (Leydon et al., 2013; Liang et al., 2013). These pollen-specific GAMYB genes are negatively regulated by a ternary complex of WRKY2, WRKY34, and the pollen-specific VQ motif-containing protein VQ20 (Lei et al., 2018, 2017). Moreover, the temporal control of WRKY2/34-VQ20 ternary complex activity by MITOGEN-ACTIVATED PROTEIN KINASE3 (MPK3)/MPK6mediated phosphorylation is a compelling example of the post-translational regulation of transcription in developing pollen (Guan et al., 2014).

[Insert Figure 4 here]

Figure 4. Overview of the morphological stages and genetic pathways regulating male gametophyte development in Arabidopsis thaliana. Polarised microspores (light blue) undergo a highly asymmetric division to produce a bicellular pollen grain with a small generative cell (pink), engulfed within the vegetative cell (dark blue). The generative cell undergoes mitotic division to produce two differentiated sperm cells (red). Genes and regulatory pathways with important functions are shown with direct interactions indicated by solid arrows. The major regulatory pathways indicated are (1), the WRKY2/34-MIKC* network in the vegetative cell, (2), the DUO1-DAZ1 differentiation network in germline cells, and (3), the FBL17-KRPS-CDKA;1-RBR1-E2F G1/S-phase regulatory module. Physical interactions between proteins are denoted by double dashes. Indirect regulatory pathways are indicated with dotted lines. Cell cycle phases (G1, S, G2) are labelled. Pollination and fertilization events indicated with grey dotted lines. (1) AtMIKC* MADS-domain protein (AGL65, AGL66 and AGL104) complexes repress early genes and activate late pollen genes in the vegetative cell. Pollen-specific GAMYB genes (MYB97, MYB101 and MYB120) are 
negatively regulated by WRKY2 and WRK34 via interaction with the pollen-specific VQ motif-protein VQ20 (Lei et al., 2018, 2017). WRKY2/34-VQ20 complex activity is regulated by MPK3/MPK6-mediated phosphorylation (Guan et al., 2014). (2) DUO1 controls gamete specification genes, including $D A Z 1$ and $D A Z 2$ (DAZ1/2), which counteract repressive mechanisms (R) via EAR-dependent interaction with the corepressor TPL. Through this mechanism, $D A Z 1 / 2$ promote the $\mathrm{G} 2 / \mathrm{M}$-phase accumulation of mitotic cyclins, generative cell division, and the DUO1-dependent activation of gamete differentiation genes and DUO1 turnover (Borg et al., 2014). (3) CDKA activity and generative cell cycle progression are maintained by the proteasome-dependent degradation of CDK inhibitors (KRPs) by the $\mathrm{SCF}^{\mathrm{FBL} 17}$ (Gusti et al., 2009; Kim et al., 2008). The transient expression of FBL17 in the generative cell promotes G1/S transition, while KRPs persist in the vegetative cell (Kim et al., 2008). The FBL17-KRPS-CDKA;1 cascade is linked to the RBRl-E2F pathway to form a general G1/S regulatory module that also functions in microspores (Zhao et al., 2012).

\subsection{Chromatin remodelling in male gametophyte development}

Chromatin organisation differs dramatically between the two different cell types of angiosperm pollen. The vegetative cell has diffuse nuclear chromatin, whereas sperm cell nuclei possess highly compact chromatin, and these differences can be traced to asymmetric microspore division. After formation of the vegetative cell, centromeric heterchromatin is gradually decondensed, coincident with the loss of the histone histone H3-like variant CENH3 from centromeres and repressive histone $\mathrm{H} 3$ lysine 9 di-methylation (H3K9me2) marks (Schoft et al., 2009). The loss of CENH3 is consistent with terminal differentiation of the vegetative cell, while germ cells maintain centromeric CENH3 and their ability to divide (Ingouff et al., 2006; Schoft et al., 2009). CENH3 removal from centromeres was shown to require the CDC48A AAA-ATPase molecular chaperone and a pair of interacting small ubiquitin-like modifier (SUMO) adaptors, NPL4A and NPL4B (Mérai et al., 2014). The 
CDC48 $\mathrm{A}^{\mathrm{NPL} 4}$ complex is proposed to bind and promote active unloading of sumoylated CENH3, while CDC48A $\mathrm{APL}^{\mathrm{NP}}$-mediated decondensed centromeric heterochromatin was also proposed to "euchromatinize" rDNA loci to facilitate rRNA gene transcription to support the high metabolic needs of pollen tubes (Mérai et al., 2014). In this regard, it is interesting that CENH3 is not excluded from centromeres in vegetative cell nuclei of rye and barley where repressive H3K9me2 marks persist (Houben et al., 2011; Pandey et al., 2013). In a survey of immunodetected chromatin marks reported for pollen of different species, there was otherwise general agreement on their prevalence, with notable differences between eudicots and monocots (Borg \& Berger, 2015). Although only monocots were studied, repressive H3K27me3 marks were enriched in subtelomeric chromatin and specific for the vegetative cell (Houben et al., 2011; Pandey et al., 2013; Sano \& Tanaka, 2010).

The chromatin of male germ cells shows dynamic changes in histone composition which varies significantly among angiosperms (reviewed in Borg \& Berger, 2015). Generative cells of lily incorporate distinct histone $\mathrm{H} 2 \mathrm{~A}, \mathrm{H} 2 \mathrm{~B}$, and $\mathrm{H} 3$ variants compared with those of somatic tissues (Ueda et al., 2000; Ueda \& Tanaka, 1994; Xu et al., 1999). While chromatin of $A$. thaliana microspores is mainly composed of $\mathrm{H} 3.1$ and $\mathrm{H} 3.3$ histone variants, sperm cell chromatin is strongly biased towards H3.3 and H3.10 variants (Borg \& Berger, 2015; Okada et al., 2005). Consequently, the dynamics of histone variants are thought to be linked to chromatin reprogramming and the compaction of the sperm cell genome (Borg \& Berger, 2015). These roles may arise though functional differences exhibited by histone variants. In particular, the abundant germline-specific histone $\mathrm{H} 3$ variant $\mathrm{H} 3.10$ is proposed to reshape the chromatin landscape by conferring immunity to the repressive chromatin mark H3K27me3 (Borg \& Berger, 2015). The absence of immunodetected H3K27me3 marks observed for germline cells of several monocots is in accord with this notion. Unexpectedly, an insertion mutant in the HTR 10 gene, encoding H3.10, did not show an obvious phenotype, suggesting functional compensation among germline histones (Okada et al., 2005). There is also evidence 
that rice sperm cells express an unique and diverse combination of histone variants, highlighting the differing chromatin landscapes of sperm among angiosperms (Anderson et al., 2013; Russell et al., 2012). In addition to potential roles in chromatin compaction, germline-specific histones might function to remove somatic chromatin marks to facilitate the specification of germline fate and/or to allow resetting of the chromatin state prior to fertilization (see Borg \& Berger, 2015).

2.5 Communication between non-germ and germ cells

Angiosperm pollen is a functional unit in which the vegetative cell nourishes, protects, and transports the germ cells to the embryo sac via the pollen tube. An intrinsic feature of this 'cell within a cell' architecture is the reliance of the germline on the vegetative cell for the transfer of nutrients and biomolecules. This unilateral dependence is illustrated by genetic ablation studies, in which the expression of diptheria toxin A-chain (DTA) was restricted to each cell-type. When vegetative cell development was arrested with DTA, generative cells were not engulfed and most rapidly lost viability (Twell, 1995), but when DTA was used to block germline development, pollen matured normally and discharged single gametes into the embryo sac (Frank \& Johnson, 2009). Similarly, pollen tubes of single-celled pollen mutants are guided to the ovule and are competent to discharge their contents in the absence of gametes (Glöckle et al., 2018; Zhang et al., 2017).

The vegetative nucleus and generative cell or sperm cell pair are also physically linked in an assemblage known as the male germ unit (Dumas et al., 1985; Jensen \& Fisher, 1970; Russell \& Cass, 1981). This structure is established in bicellular pollen and is maintained until discharge of the pollen tube contents into the embryo sac (reviewed in McCue et al., 2011; Mogensen, 1992). The potential for molecular communication between pollen cell types, via the physical extension linking one of the sperm cell pair to the vegetative nucleus, was first postulated by Mogensen (1992). Plasmodesmata-like channels between the two cells have not been identified using rapid freeze fixation and freeze substitution, which avoids artifacts 
caused by conventional methods (Cresti et al., 1987), although the topic remains controversial (see McCue et al., 2011). However, it is evident that mechanisms exist to transport both mRNAs and short interfering RNAs (siRNAs) from the vegetative cell to the developing germline.

While studying the expression of the sperm cell-enriched ABA-related protein phosphatase gene ABA-HYPERSENSITIVE GERMINATION3 (AHG3), Jiang and coworkers (2015) unexpectedly found that the $A H G 3$ promoter was transcriptionally active in the vegetative cell, whereas a translational fusion protein was localized to sperm (Jiang et al., 2015). The authors provided evidence that $A H G 3$ transcripts move from the vegetative cell to sperm cells, and that transport requires sequences in both the 5' UTR and coding region. The mechanisms involved and the extent of communication via this route are not yet clear, but these results document an additional role for the vegetative cell in shaping the sperm cell transcriptome (Jiang et al., 2015).

Different classes of small RNAs are present in vegetative cells and sperm cells (reviewed in He et al. 2015). These span most conserved microRNA (miRNA) families and include biogenesis genes such as DICER-LIKE1 (DCL1) (Borges et al., 2011; Creasey et al., 2014; Grant-Downton et al., 2009; Slotkin et al., 2009). Based on the de-repression of transposable elements (TEs) in the vegetative cell, and the appearance of corresponding $21 \mathrm{nt}$ siRNAs in sperm cells, it was proposed that siRNAs could move between the vegetative cell and sperm cells of A. thaliana to maintain TE silencing in sperm (Slotkin et al., 2009). Evidence in support of this proposal was that artificial miRNAs expressed under control of the vegetative cell-expressed tomato LAT52 promoter could repress gene expression in the sperm cells (Slotkin et al., 2009). However, the LAT52 promoter is first active in the microspores of $A$. thaliana (Eady et al., 1995), raising the possibility of inheritance of miRNAs by the germline. Truly vegetative cell-specific promoters also failed to silence targets in the germline, indicating that miRNA cannot move between cells (Grant-Downton et al., 2009). However, 
recent experiments utilising robustly cell-specific promoters demonstrate that siRNAs produced from vegetative cell transcripts can silence TE reporters in sperm cells (Martínez et al., 2016). Thus, siRNAs, but not miRNAs, are trafficked into the germline, although the mechanisms involved in transfer, or which discriminate between these two classes of small RNAs, remain to be discovered.

\section{Molecular evolution of the male germline}

3.1 Motile plant and animal sperm share common features

The morphology of sperm cells has changed markedly during the evolution of land plants. Excellent reviews by Renzaglia \& Garbary (2001) and Southworth \& Cresti (1997) discuss the diversity, development, and evolution of land plant sperm. Only selected aspects and recent molecular and genetic data are highlighted here.

Biflagellate spermatozoids with condensed chromatin, packaged into an elongated and coiled nucleus, are produced by advanced charophyte algae and bryophytes (Figure 3A). These biflagellated spermatozoids are not only superficially reminiscent of mammalian spermatozoa, but recent analysis of antheridia-enriched transcripts in M. polymorpha, revealed homologs of a number of motility-related genes that are absent from angiosperms (Higo et al., 2016). These include the mammalian Parkin co-regulated gene $(\mathrm{Mp} P A C R G)$, responsible for axoneme formation (Ikeda et al., 2007; Lorenzetti et al., 2004; Yanagimachi et al., 2004), light chains of the inner arm dynein of the axoneme (MpCL7), adenylate cyclase, required for sperm motility (Schmid et al., 2007), and human CHD5, which is required for spermatid chromatin remodelling and condensation (Li et al., 2014; Zhuang et al., 2014).

One of the most striking similarities between spermatozoa of most animals and the spermatozoids of charophytes and basal land plants is their nuclear chromatin compaction. This character is thought to improve the hydrodynamic properties of sperm (Erenpreiss et al., 2006), and to protect the genome against irradiation damage, nuclease degradation and 
mechanical forces (Rathke et al., 2010; Wykes and Krawetz, 2003). In animal sperm, histonebased nucleosomes are replaced by highly basic proteins called protamines (Johnson et al., 2011; Meistrich et al., 2003). Protamine-like proteins can be found in spermatozoids of algae (Chara corallina), bryophytes (M. polymorpha) and ferns (M. vestitia), but not in seed plants (reviewed in Borg \& Berger 2015). In M. polymorpha sperm, histones are replaced by protamines and the exchange mechanism involves transitory proteins of intermediate size and basicity, similar to the situation in animals (Reynolds \& Wolfe, 1984, 1978). Variation in the coexistence of intermediate histone/protamine proteins and somatic histones indicates a remarkable adaptation of nucleoprotein composition exchange mechanism among early divergent species (Borg \& Berger, 2015).

The spermatozoids of charophyte algae and basal land plants share the common feature of cytoplasmic reduction via macroautophagy, with animal spermatozoa. Macroautophagy is controlled by autophagy related proteins (ATGs) in mice as well as in the moss P. patens, suggesting recurrent adoption of an ancestral mechanism. ATG5 and ATG7 are essential for sperm fertility in $P$. patens, similar to the requirement for ATG7 in mice. Impaired autophagy is thought to impact microtubule and flagella development, as well as nuclear packaging, by reduced clearance of cytoplasmic repressors (Sanchez-Vera et al., 2017). In angiosperms, ATG genes evidently do not influence pollen morphology, but indirectly support pollen maturation and germination. Knock-out of rice $A T G 7$ resulted in sporophytic pollen defects, arising from reduced autophagic degradation in the anther tapetum (Kurusu et al., 2014). Furthermore, pollen germination defects observed in A. thaliana ATG6 mutants are gametophytically determined, but attributed to functions other than autophagy (Fujiki et al., 2007). Thus, the role of autophagy in male reproduction has diversified with the evolution of non-motile sperm in seed plants. Cytoplasmic reduction is likely to be less important for the larger and non-motile sperm of seed plants than for spermatozoids of basal land plants. However, there is evidence that sperm cells of some angiosperms reduce their cellular volume by shedding cytoplasmic vesicles into the vegetative cell (Yu \& Russell, 1992). This may 
assist in sperm cell movement within the pollen tube and could limit the paternal cytoplasmic contribution to the zygote.

A signal perception apparatus used for chemotactic navigation by land plants may operate in mammalian sperm. The GLUTAMATE-RECEPTOR-LIKE (GLR) ion-channels are essential for moss spermatozoids to navigate to archegonia (Ortiz-Ramírez et al., 2017). In flowering plants, where immotile sperm no longer require chemoattraction, GLRs have been redeployed to regulate pollen tube growth and navigation in response to chemotactic factors released by the pistil (Michard et al., 2011). Although GLRs are expressed in mammalian sperm, their functions are currently unknown (Hu et al., 2004).

In monilophytes, spermatozoids can develop over 100 flagella (Figure 3B; Myles \& Hepler, 1977), while those of the non-siphonogamous gymnosperms, possess much larger multiflagellate sperm, with around 1000 flagella for G. biloba (Figure 3C; Gifford \& Lin, 1975). The cycads have the largest sperm with a diameters of 200-500 $\mu \mathrm{m}$ and an estimated 40,000 flagella for the genus Zamia (Norstog, 1975). The increase in flagella number is associated with increased sperm cell volume, the absence of coiled morphology and reduced chromatin compaction. With the loss of sperm cell motility in siphonogamous gymnosperms (e.g. in G. gnemon and the genus Ephedra) and angiosperms, only the angiosperms possess highly condensed chromatin (see Southworth \& Cresti 1997), indicating that chromatin compaction may be atavistic in angiosperms. The sperm cells of flowering plants also possess a distinctive cytoskeleton when compared to somatic cells (reviewed in Palevitz \& Tiezzi, 1992; Southworth \& Cresti, 1997). This consists of microtubule bundles that form a basket or cage around the nucleus. This internal cytoskeleton is thought to be involved in the establishment or maintenance of cell shape, because isolated sperm and generative cells become spheroidal and lose microtubule bundles (Mogensen, 1992; Palevitz \& Tiezzi, 1992). It remains unclear whether flowering plant sperm evolved from motile sperm by loss of flagella, but distinct microtubule organizing centers such as blepharoplasts, centrioles, or 
basal bodies are absent and microtubules do not occur regularly or in a 9 plus 2 arrangement (Palevitz \& Tiezzi, 1992).

In summary, the shared features of motile plant and animal sperm, like flagella-based locomotion, protamine-mediated chromatin compaction or cytoplasmic reduction via autophagy, have evolved independently. Chromatin compaction mediated by protamines was apparently lost in vascular plants, while flagellar-based motility was lost in some gymnosperms and in the common ancestor of angiosperms. Furthermore, immotile plant sperm evolved a unique microtubule cytoskeleton with uncertain origins. Autophagosomal pathways and chemoattractant perception were also redeployed to support the complex reproductive systems of angiosperms.

\subsection{Gene expression in male germ cells}

Transcriptome data for reproductive gametophyte stages of basal land plant species is limited to the water fern $M$. vestita and the liverwort M. polymorpha. A remarkable feature of spermatogenesis in M. vestita is that the process is largely under post-transcriptional control. This facilitates rapid spermatogenesis, largely independent of the external environment and also shifts the control of gametophyte fitness towards the sporophyte. Messenger RNAs required for sperm cell development are stored in microspores as partially processed premRNAs. After spores are rehydrated, pre-mRNAs are unmasked, processed, and translated according to a precise spatiotemporal pattern. Stored transcripts include those encoding tubulins and centrins (Tsai et al., 2004), as well as proteins important for mitosis and flagella formation, such as kinesins (Tomei \& Wolniak, 2016). More detailed information is available for the transcriptome of developing antheridia of M. polymorpha (Higo et al., 2016). Among more than 700 genes specifically or preferentially expressed in antheridia, are genes associated with sperm motility (see section 3.1), cell cycle control, reproduction, regulation of gene expression and epigenetic processes, including homologs of angiosperm genes essential for male gametophyte and gamete formation (see section 3.3). 
The male germ cells of angiosperms possess a distinct transcriptome compared to those of other tissues or organs. Data from cDNA-sequencing are available for isolated generative cells or sperm cells of several species (reviewed in Russell \& Jones, 2015; Rutley \& Twell, 2015). Larger scale microarray studies of sperm cells of $A$. thaliana or rice detected 5,829 or 10,732 different transcripts respectively (Borges et al., 2008; Russell et al., 2012). A similar proportion of these transcripts (18-22\%) were absent from seedlings of both species and were thus considered specific or enriched in sperm. In an independent RNA-sequencing study, 16,985 transcripts were reliably detected in rice sperm, while 18,611 transcripts were present in a vegetative cell-enriched fraction (Anderson et al., 2013). Similar to A. thaliana, male gamete-enriched transcripts in rice are associated with ubiquitin-mediated proteolysis, DNA modification, and chromatin remodelling (reviewed in Russell \& Jones, 2015; Rutley \& Twell, 2015). Ubiquitin mediated protein turnover is critical for male gametogenesis, and disruption of the ubiquitin proteasome system impairs male gametophyte development in $A$. thaliana (Doelling et al., 2007; Gallois et al., 2009). Further compelling evidence for the importance of the ubiquitin proteasome system in gametogenesis includes the role of the $\mathrm{SCF}^{\mathrm{FBL17}} \mathrm{E} 3$ ubiquitin ligase complex, which promotes generative cell cycle progression (see section 2.2, Figure 4).

Changes in the relationship between cell cycle progression and sperm development have led to different ontogenetic patterns in seed plants, and this is important for gamete synchrony at fertilization (Friedman, 1999). In essence, the timing of generative cell division and the stage of the cell cycle of sperm cells vary in relation to pollination and fertilization (Friedman, 1999). For example, A. thaliana and P. zeylanica sperm cells are in S-phase at anthesis and reach the G2-phase prior to fertilization, whereas grass species like rice and maize remain in G1-phase until fertilization (Friedman, 1999; Gou et al., 2009). In accord with predictions based on these ontogenetic patterns, cell cycle gene expression in sperm cells differs between species. Consequently, S-phase associated cell cycle genes are enriched in sperm cells of $A$. thaliana (Borges et al., 2008) and P. zeylanica (Gou et al., 2009), but not in rice (Anderson et 
al., 2013) and transcripts of G1-type cyclins were not detected in isolated sperm of maize (Sauter et al., 1998).

Angiosperm male gametes express a full complement of DNA and chromatin modifying proteins to support gametogenesis and transgenerational epigenetic processes (Anderson et al., 2013; Borges et al., 2008). In common with A. thaliana, rice sperm cells preferentially express DNA METHYLTRANSFERASE1 (MET1), consistent with the maintenance and epigenetic inheritance of CG-methylation through the male germline (Calarco et al., 2012; Saze, 2008; Saze et al., 2003). Moreover, silencing of the transcription factor ARID1 in A. thaliana sperm cells is dependent upon MET1 and linked to gene body specific CGmethylation ( $\mathrm{Li}$ et al., 2017). The epigenetic remodeling of sperm chromatin is also thought to involve the creation and removal of histone marks and the expression of histone lysine methyl transferase and demethylase enzymes (see Anderson et al., 2013). Further aspects of chromatin organization in the male germ cells of angiosperms are discussed in section 2.4. A key feature is that distinct histone variants and several core histones are specifically or preferentially expressed in the male germline and can be unique even among angiosperms. In contrast, the amino acid sequence of the M. polymorpha antheridium-specific H3 variant does not differ from that of somatic H3.3 (Higo et al., 2016). This indicates that the specialized roles proposed for unique histone variants of flowering plant sperm (section 2.4) may not operate in bryophytes and that the control of histone H3.3 abundance may be more important for gametogenesis.

Adaptation of the transcriptome of male gametes is evident from the recruitment of new genes to a sperm-cell network in A. thaliana. The SHORT SUSPENSOR (SSP) gene of A. thaliana encodes a membrane-associated IRAK/Pelle-like kinase, which regulates YODA mitogenactivated protein kinase signalling in early embryogenesis (Bayer et al., 2009). SSP is specifically transcribed in sperm, but transcripts are only translated after transmission to the zygote. Phylogenetic analysis has revealed the divergence and neofunctionalization of SSP 
following a polyploidy event in Brassicaceae (Liu \& Adams, 2010). Moreover, the recruitment of $S S P$ to a sperm cell-specific network, leading to the paternal control of zygote development, is a recent evolutionary event (Liu \& Adams, 2010).

\subsection{The evolution of transcription factors regulating male gametogenesis}

Comparative studies are starting to uncover the evolutionary origins of transcriptional networks in male gametophyte development. Functionally conserved modules, as well as the rewiring of gametophyte and germline gene networks, have been described.

Recent studies of MIKC-type MADS-domain transcription factors illustrate how closely related gene families can follow distinct evolutionary trajectories. Three of the six member MIKC $^{\mathrm{C}}$-type MADS-domain family in P. patens are redundantly required for the formation of sperm with functional flagella (Koshimizu et al., 2018). Mutations in these genes also disturb cell division and growth in the stems of gametophores, which is important for the uptake of external water and for fertilization. In mutants deleted for all six P. patens $\mathrm{MIKC}^{\mathrm{C}}$-type genes, the expression of flagellum-related genes is disturbed, leading to defective sperm movement and less efficient entry of sperm into archegonia. In Chara globularis, MIKC ${ }^{\mathrm{C}}$-type MADSbox genes are expressed during sperm differentiation, suggesting an ancient and conserved function in the regulation of flagellum genes (Tanabe et al., 2005). In angiosperms, MIKC ${ }^{\mathrm{C}}$ type MADS-box genes seem to have lost their role in fertilization, but through amplification and neofunctionalization, these genes still control cell division and organ growth and identity (Koshimizu et al., 2018). In contrast, the closely related MIKC* MADS-genes are thought to have retained conserved roles in the gametophyte (Kwantes et al., 2012). MIKC* MADSgenes evolved from an $\mathrm{MIKC}^{\mathrm{C}}$-like ancestor (Henschel et al., 2002) and function in heteromeric complexes regulating pollen development (see 2.4). Unlike the MIKC ${ }^{\mathrm{C}}$ class, the MIKC* MADS-genes did not acquire sporophytic expression in angiosperms (Kwantes et al., 2012). Although the function of MIKC* MADS-genes in bryophytes is yet to be determined, the successful complementation of $A$. thaliana mutants lacking MIKC* complexes with the 
single $M$. polymorpha ortholog, supports a conserved molecular mechanism in land plants (Zobell et al., 2010).

Comparative analysis is also beginning to uncover the evolutionary origins of germline specification factors. In $M$. polymorpha, the bHLH-family transcription factor BNB is required for the initiation of specialised male and female reproductive shoots (gametangiophores), which bear male and female gametangia, while two A. thaliana orthologues of $B N B$ are redundantly required for male gametogenesis (Yamaoka et al., 2018). $\mathrm{Mp} B N B$ is expressed in gametangiophore and gametangia initial cells of both sexes, and in the germ cell lineage of antheridia and archegonia. Although $\mathrm{Mp} B N B$ is expressed in immature eggs cells and in spermatogenous cells prior to proliferative cell divisions, it is not maintained in maturing gametes. In A. thaliana, AtBNB1 expression is restricted to the generative cell of developing pollen and is absent from sperm cells. This shift in expression pattern of $B N B$ from M. polymorpha to A. thaliana reflects the absence of gametangiophores and antheridal initial cells from angiosperms, and the maintenance of expression in the immature sperm cell lineage (i.e. generative cells) (Figure 2B and F). Mutation of both $A t B N B$ paralogs abolishes the expression of the sperm cell differentiation marker H3.10, which is under the control of the DUO1-DAZ1 module (Yamaoka et al., 2018). Moreover, DUO1 and DAZ1 are specifically expressed in antheridia of M. polymorpha (Higo et al., 2016). The overlapping expression of $B N B$ and $D U O 1$ in generative cells of $A$. thaliana highlights the potential role of $B N B$ as a conserved upstream regulator of the DUO1-DAZ1 module (Figure 4).

DUO1 and DAZ1 orthologs are also co-expressed in sperm cells of rice, together with homologues of several DUO1 target genes, indicating conservation of a key germline regulatory network in angiosperms (Li et al., 2010; Russell et al., 2012; Rutley \& Twell, 2015). The antheridia-specific expression of the single copy $D U O 1$ and $D A Z 1$ orthologs in $M$. polymorpha (Higo et al., 2016) and the presence of two DUO1 orthologues in P. patens 
(Brownfield et al., 2009a), suggest a conserved role for the DUO1-DAZ1 module in bryophytes. Moreover, homologs of several genes essential for angiosperm gametogenesis are specifically or preferentially expressed in antheridia of $M$. polymorpha (Higo et al., 2016). These include homologs of the DUO1-target genes, GEX2 and GCS1/HAP2, which highlights the question of when these fertilization genes were recruited to the DUO1-DAZ1 network.

There is growing evidence for the adaptation and rewiring of germline gene networks in the 450-500 million years of evolution separating liverworts and angiosperms. The transcription factors $R K D$ and $B N B$ evolved sex-specific roles in angiosperms from broader ancestral roles in bryophytes. In M. polymorpha, $\mathrm{Mp} R K D$ is required for egg and sperm differentiation, while in A. thaliana, RKD family genes are associated with embryogenesis and egg cell formation, but not with sperm differentiation (Koi et al., 2016; Rövekamp et al., 2016). Similarly, the $M$. polymorpha bHLH protein BNB has an essential role in male and female gametangia development, while the function of the A. thaliana orthologues $(B N B 1 / 2)$ is restricted to the male germline (Yamaoka et al., 2018). Evolutionary rewiring has also changed the regulatory network of GAMYB transcription factors. GAMYB proteins have retained an ancient role in the control of sporopollenin biosynthesis, which is required for spore and pollen grain development in land plants (Aya et al., 2011, 2009). In vascular plants, sporopollenin biosynthesis controlled by the GAMYB transcriptional network was adopted by the newly evolved gibberellin (GA) signal transduction module (Aya et al., 2011). Duplication and neofunctionalisation diversified the roles of GAMYBs in angiosperms to include inflorescence and anther development (Gocal et al., 2001; Kaneko et al., 2004), pollen tube differentiation (see section 2.3, Figure 4; Leydon et al., 2013; Liang et al., 2013), and nonreproductive pathways, including GA-signalling during seed germination (Tsuji et al., 2006)

\section{Perspective}


The evolutionary history of male gametogenesis has left a trail of adaptive changes, which enabled plants to safeguard their reproduction on land. Our understanding of these changes has progressed with advances in microscopy, genetics, and omics-approaches, but knowledge at the molecular level has been largely limited to angiosperms. Important evolutionary questions remain unresolved. How and when did anisogamy evolve in streptophyte algae? Which regulators and gene networks are responsible for the distinct development of male and female gametangia? A central question in angiosperms is how the germline sensu stricto is specified by asymmetric division of the microspore. The role and diversity of the changing chromatin landscape of germline versus non-germ cells is another fundamental issue for which there is limited knowledge. Given the reduced costs of DNA sequencing, progress can be made to clarify the origins and the evolution of genes and networks responsible for sexual reproduction. Sexual reproduction for most basal charophytes is unknown, and nuclear genome sequences are only available for one charophyte species, Klebsomidium nitens (Hori et al., 2014). Whole genome sequencing and transcriptome studies of gametangia of charophytes, as well as basal land plants, like hornworts, will help to uncover pathways crucial for reproductive adaptation to terrestrial habitats. The availability of a full range of tools for gene manipulation in bryophytes, like $M$. polymorpha and $P$, patens, are already beginning to advance understanding of reproductive development and the adaptations of basal land plants (Koi et al., 2016; Koshimizu et al., 2018; Rövekamp et al., 2016; Yamaoka et al., 2018). These comparative studies span the major reproductive transitions, from exo- to endosporic gametophytes, from motile to immotile sperm, and the innovation of double fertilisation. These key transitions are expected to involve the rewiring of gene networks such as those controlled by deeply conserved regulators such as $B N B$ (Yamaoka et al., 2018), DUO1 and DAZ1 (Brownfield et al., 2009a; Higo et al., 2016).

Collaborative efforts, such as the multinational EVOREPRO consortium (http://www.evorepro.org/), are providing new tools for comparative transcriptomics. Transcriptome data from various stages of gametogenesis from model and from crop plants, 
representing major phylogenetic clades of land plants, will accelerate discovery through an open source database (Proost \& Mutwil, 2018). The inclusion of data from M. polymorpha and $P$, patens, alongside Amborella trichopda, maize, rice, A. thaliana, and tomato, will provide new opportunities to identify novel and missing components involved in gamete development and fertilization. Moreover, rapidly developing methods, like chromatin immunoprecipitation sequencing (ChIPseq) (Kaufmann et al., 2010) and TransposaseAccessible Chromatin using sequencing (ATACseq) (Bajic et al., 2018; Buenrostro et al., 2013; Lu et al., 2017), offer new horizons in the decoding of pollen and gamete regulatory networks. These approaches would allow the binding between transcription factors and their target loci to be resolved, and to decipher how these interactions are integrated with the changing chromatin landscape. The precision of such methods will be further enhanced by the use of fluorescence-activated cell sorting (FACS) and single cell transcriptome analysis (Borges et al., 2012; Santos et al., 2017; Schoft et al., 2015). Future studies using established and newly emerging models promise major advances in our understanding of the development and evolution of male gametogenesis in plants.

\section{Acknowledgements}

We thank all members of the EVOREPRO consortium for their cooperation, stimulating discussion and for sharing of unpublished results. We also thank Karen Renzaglia (Southern Illinois University) and Kazuo Okada (TokyoCinema Inc.) for granting reprint permission to include motile sperm micrographs. DH was supported within the ERA-CAPS project EVOREPRO by the Biotechnology and Biological Research Council (BB/N005090/1 to DT).

\section{References}

Adamczyk, B.J.\& Fernandez, D.E. (2009). MIKC* MADS Domain Heterodimers Are Required for Pollen Maturation and Tube Growth in Arabidopsis. Plant Physiology 149, $1713-1723$. 
An, R., Liu, X., Wang, R., Wu, H., Liang, S., Shao, J. et al. (2014). The over-expression of two transcription factors, $A B S 5 / b H L H 30$ and $A B S 7 / M Y B 101$, leads to upwardly curly leaves. PLOS ONE 9, e107637.

Anderson, S.N., S., Johnson, C.S., Jones, D.S., Conrad, L.J., Xiaoping, G., Russell, S.D. et al. (2013). Transcriptomes of isolated Oryza sativa gametes characterized by deep sequencing: evidence for distinct sex-dependent chromatin and epigenetic states before fertilization. The Plant Journal 76, 729-741.

Aw, S.J., Hamamura, Y., Chen, Z., Schnittger, A.\& Berger, F. (2010). Sperm entry is sufficient to trigger division of the central cell but the paternal genome is required for endosperm development in Arabidopsis. Development 137, 2683-2690.

Aya, K., Hiwatashi, Y., Kojima, M., Sakakibara, H., Ueguchi-Tanaka, M., Hasebe, M. et al. (2011). The Gibberellin perception system evolved to regulate a pre-existing GAMYBmediated system during land plant evolution. Nature Communications 2, 544.

Aya, K., Ueguchi-Tanaka, M., Kondo, M., Hamada, K., Yano, K., Nishimura, M. et al. (2009). Gibberellin modulates anther development in rice via the transcriptional regulation of GAMYB. The Plant cell 21, 1453-1472.

Bajic, M., Maher, K.A.\& Deal, R.B. (2018). Identification of Open Chromatin Regions in Plant Genomes Using ATAC-Seq. Methods in molecular biology 1675, 183-201.

Bateman, R.M. \& DiMichele, W.A. (1994). Heterospory: The most iterative key innovation in the evolutionary history of the plant kingdom. Biological Reviews 69, 345-417.

Bayer, M., Nawy, T., Giglione, C., Galli, M., Meinnel, T. \& Lukowitz, W. (2009). Paternal control of embryonic patterning in Arabidopsis thaliana. Science 323, 1485-1488.

Berger, F. \& Twell, D. (2011). Germline Specification and Function in Plants. Annual Review of Plant Biology 62, 461-484.

Borg, M. \& Berger, F. (2015). Chromatin remodelling during male gametophyte development. The Plant Journal 83, 177-188.

Borg, M., Brownfield, L., Khatab, H., Sidorova, A., Lingaya, M. \& Twell, D. (2011). The 
R2R3 MYB Transcription Factor DUO1 Activates a Male Germline-Specific Regulon Essential for Sperm Cell Differentiation in Arabidopsis. The Plant Cell 23, 534-549.

Borg, M., Rutley, N., Kagale, S., Hamamura, Y., Gherghinoiu, M. \& Kumar, S. et al. (2014).

An EAR-Dependent Regulatory Module Promotes Male Germ Cell Division and Sperm Fertility in Arabidopsis. The Plant Cell 26, 2098-2113.

Borges, F., Gardner, R., Lopes, T., Calarco, J.P., Boavida, L.C., Slotkin, R.K. et al. (2012).

FACS-based purification of Arabidopsis microspores, sperm cells and vegetative nuclei. Plant Methods 8, 44.

Borges, F., Gomes, G., Gardner, R., Moreno, N., McCormick, S., Feijó, J.A. et al. (2008).

Comparative Transcriptomics of Arabidopsis Sperm Cells. Plant Physiology 148, 11681181.

Borges, F., Pereira, P.A., Slotkin, R.K., Martienssen, R.A.\& Becker, J.D. (2011). MicroRNA activity in the Arabidopsis male germline. Journal of Experimental Botany 62, 16111620.

Bowman, J.L., Kohchi, T., Yamato, K.T., Jenkins, J., Shu, S., Ishizaki, K. et al. (2017). Insights into Land Plant Evolution Garnered from the Marchantia polymorpha Genome. Cell 171, 287-304.

Brewbaker, J.L. (1967). The Distribution and Phylogenetic Significance of Binucleate and Trinucleate Pollen Grains in the Angiosperms. American Journal of Botany 54, 10691083.

Brooks, J.\& Shaw, G. (1978). Sporopollenin: A review of its chemistry, palaeochemistry and geochemistry. Grana 17, 91-97.

Brownfield, L., Hafidh, S., Borg, M., Sidorova, A., Mori, T. \& Twell, D. (2009a). A Plant Germline-Specific Integrator of Sperm Specification and Cell Cycle Progression. PLOS Genetics 5, e1000430.

Brownfield, L., Hafidh, S., Durbarry, A., Khatab, H., Sidorova, A., Doerner, P. et al. (2009b). Arabidopsis DUO POLLEN3 Is a Key Regulator of Male Germline Development and 
Embryogenesis. The Plant Cell 21, 1940-1956.

Buenrostro, J.D., Giresi, P.G., Zaba, L.C., Chang, H.Y. \& Greenleaf, W.J. (2013).

Transposition of native chromatin for fast and sensitive epigenomic profiling of open chromatin, DNA-binding proteins and nucleosome position. Nature Methods 10, $1213-$ 1218.

Calarco, J.P., Borges, F., Donoghue, M.T.A., Van Ex, F., Jullien, P.E., Lopes, T. et al. (2012). Reprogramming of DNA methylation in pollen guides epigenetic inheritance via small RNA. Cell 151, 194-205.

Carmichael, J.S. \& Friedman, W.E. (1995). Double Fertilization in Gnetum gnemon: The Relationship between the Cell Cycle and Sexual Reproduction. The Plant Cell 7, 19751988.

Chen, Y.C. \& McCormick, S. (1996). sidecar pollen, an Arabidopsis thaliana male gametophytic mutant with aberrant cell divisions during pollen development. Development 122, 3243-3253.

Chen, Z., Hafidh, S., Poh, S.H., Twell, D. \& Berger, F. (2009). Proliferation and cell fate establishment during Arabidopsis male gametogenesis depends on the Retinoblastoma protein. Proceedings of the National Academy of Sciences of the United States of America 106, 7257-7262.

Creasey, K.M., Zhai, J., Borges, F., Van Ex, F., Regulski, M., Meyers, B.C. et al. (2014). miRNAs trigger widespread epigenetically-activated siRNAs from transposons in Arabidopsis. Nature 508, 411-415.

Cresti, M., Lancelle, S.A. \& Hepler, P.K. (1987). Structure of the generative cell wall complex after freeze substitution in pollen tubes of Nicotiana and Impatiens. Journal of Cell Science 88, 373-378.

Delwiche, C.F. (2016). The Genomes of Charophyte Green Algae, in: Rensing, S. (Ed.), Genomes and Evolution of Charophytes, Bryophytes, Lycophytes and Ferns. (pp. 255270), Academic Press. 
Doelling, J.H., Phillips, A.R., Soyler-Ogretim, G., Wise, J., Chandler, J., Callis, J. et al., (2007). The Ubiquitin-Specific Protease Subfamily UBP3/UBP4 Is Essential for Pollen Development and Transmission in Arabidopsis. Plant Physiology 145, 801-813.

Dumas, C., Knox, R.B. \& Gaude, T. (1985). The spatial association of the sperm cells and vegetative nucleus in the pollen grain of Brassica. Protoplasma 124, 168-174.

Durand, E.J. (1908). The Development of the Sexual Organs and Sporogonium of Marchantia polymorpha. Bulletin of the Torrey Botanical Club 35, 321-335.

Durbarry, A., Vizir, I. \& Twell, D. (2005). Male Germ Line Development in Arabidopsis. duo pollen Mutants Reveal Gametophytic Regulators of Generative Cell Cycle Progression. Plant Physiology 137, 297-307.

Eady, C., Lindsey, K. \& Twell, D. (1995). The Significance of Microspore Division and Division Symmetry for Vegetative Cell-Specific Transcription and Generative Cell Differentiation. The Plant Cell 7, 65-74.

Engel, M.L., Holmes-Davis, R. \& McCormick, S. (2005). Green Sperm. Identification of Male Gamete Promoters in Arabidopsis. Plant Physiology 138, 2124-2133.

Erenpreiss, J., Spano, M., Erenpreisa, J., Bungum, M. \& Giwercman, A. (2006). Sperm chromatin structure and male fertility: biological and clinical aspects. Asian Journal of Andrology 8, 11-29.

Fernando, D., Quinn, C., Brenner, E. \& Owens, J. (2010). Male Gametophyte Development and Evolution in Extant Gymnosperms. In: Fernando DD (Ed) Plant Development and Evolution. International Journal of Plant Developmental Biology 4 (Special Issue 1), (pp 47-63), Global Science Books.

Ferris, P.J., Armbrust, E.V. \& Goodenough, U.W. (2002). Genetic structure of the matingtype locus of Chlamydomonas reinhardtii. Genetics 160, 181-200.

Ferris, P.J. \& Goodenough, U.W. (1997). Mating Type in Chlamydomonas Is Specified by Mid, the minus-Dominance Gene. Genetics 146, 859-869.

Ferris, P.J. \& Goodenough, U.W. (1994). The mating-type locus of Chlamydomonas 
reinhardtii contains highly rearranged DNA sequences. Cell 76, 1135-1145.

Fíla, J., Záveská Drábková, L., Gibalová, A. \& Honys, D. (2017). When Simple Meets Complex: Pollen and the -Omics BT - Pollen Tip Growth: in: Obermeyer, G., Feijó, J. (Eds.), From Biophysical Aspects to Systems Biology, (pp. 247-292). Springer International Publishing, Cham,.

Frank, A.C. \& Johnson, M.A. (2009). Expressing the Diphtheria Toxin A Subunit from the HAP2(GCS1) Promoter Blocks Sperm Maturation and Produces Single Sperm-Like Cells Capable of Fertilization. Plant Physiology 151, 1390-1400.

Friedman, L., Santa Anna-Arriola, S., Hodgkin, J. \& Kimble, J. (2000). gon-4, a cell lineage regulator required for gonadogenesis in Caenorhabditis elegans. Developmental biology $228,350-362$.

Friedman, W.E. (1999). Expression of the cell cycle in sperm of Arabidopsis: implications for understanding patterns of gametogenesis and fertilization in plants and other eukaryotes. Development 126, 1065-1075.

Friedman, W.E. (1998). The evolution of double fertilization and endosperm: an "historical" perspective. Sexual Plant Reproduction 11, 6-16.

Friedman, W.E. (1993). The evolutionary history of the seed plant male gametophyte. Trends in Ecology \& Evolution 8, 15-21.

Friedman, W.E. (1990). Double fertilization in ephedra, a nonflowering seed plant: its bearing on the origin of angiosperms. Science 247, 951-954.

Friedman, W.E. \& Gifford, E.M. (1997). Development of the Male Gametophyte of Ginkgo biloba: A Window into the Reproductive Biology of Early Seed Plants, in: Hori, T., Ridge, R.W., Tulecke, W., Del Tredici, P., Trémouillaux-Guiller, J., Tobe, H. (Eds.), Ginkgo Biloba A Global Treasure: From Biology to Medicine, (pp. 29-49), Springer Japan, Tokyo..

Fujiki, Y., Yoshimoto, K. \& Ohsumi, Y. (2007). An Arabidopsis homolog of yeast ATG6/VPS30 is essential for pollen germination. Plant physiology 143, 1132-1139. 
Furumizu, C., Alvarez, J.P., Sakakibara, K. \& Bowman, J.L. (2015). Antagonistic Roles for KNOX1 and KNOX2 Genes in Patterning the Land Plant Body Plan Following an Ancient Gene Duplication. PLOS Genetics 11, e1004980.

Gallois, J.-L., Guyon-Debast, A., Lécureuil, A., Vezon, D., Carpentier, V., Bonhomme, S. et al. (2009). The Arabidopsis Proteasome RPT5 Subunits Are Essential for Gametophyte Development and Show Accession-Dependent Redundancy. The Plant Cell 21, 442-459. Geng, S., De Hoff, P. \& Umen, J.G. (2014). Evolution of sexes from an ancestral mating-type specification pathway. PLOS Biology 12, e1001904.

Gifford, E.M. \& Foster, A.S. (1989). Morphology and evolution of vascular plants.,New York: W.H. Freeman.

Gifford, M.E. \& Lin, J. (1975). Light Microscope and Ultrastructural Studies of the Male Gametophyte in Ginkgo biloba: The Spermatogenous Cell. American Journal of Botany $62,974-981$.

Glöckle, B., Urban, W.J., Nagahara, S., Andersen, E.D., Higashiyama, T., Grini, P.E. et al., (2018). Pollen differentiation as well as pollen tube guidance and discharge are independent of the presence of gametes. Development 145.

Gocal, G.F., Sheldon, C.C., Gubler, F., Moritz, T., Bagnall, D.J., MacMillan, C.P. et al., (2001). GAMYB-like genes, flowering, and gibberellin signaling in Arabidopsis. Plant Physiology 127, 1682-1693.

Gou, X., Yuan, T., Wei, X. \& Russell, S.D. (2009). Gene expression in the dimorphic sperm cells of Plumbago zeylanica: transcript profiling, diversity, and relationship to cell type. The Plant Journal 60, 33-47.

Grant-Downton, R., Hafidh, S., Twell, D. \& Dickinson, H.G. (2009). Small RNA Pathways Are Present and Functional in the Angiosperm Male Gametophyte. Molecular Plant 2, $500-512$.

Guan, Y., Guo, J., Li, H. \& Yang, Z. (2013). Signaling in pollen tube growth: crosstalk, feedback, and missing links. Molecular Plant 6, 1053-1064. 
Guan, Y., Meng, X., Khanna, R., LaMontagne, E., Liu, Y. \& Zhang, S. (2014).

Phosphorylation of a WRKY Transcription Factor by MAPKs Is Required for Pollen Development and Function in Arabidopsis. PLOS Genetics 10, e1004384.

Gusti, A., Baumberger, N., Nowack, M., Pusch, S., Eisler, H., Potuschak, T. et al., (2009). The Arabidopsis thaliana F-box protein FBL17 is essential for progression through the second mitosis during pollen development. PLOS ONE 4, e4780.

Gutzat, R., Borghi, L. \& Gruissem, W. (2012). Emerging roles of RETINOBLASTOMARELATED proteins in evolution and plant development. Trends in plant science 17, $139-148$.

Hafidh, S., Fila, J. \& Honys, D. (2016). Male gametophyte development and function in angiosperms: a general concept. Plant Reproduction 29, 31-51.

Hamamura, Y., Saito, C., Awai, C., Kurihara, D., Miyawaki, A., Nakagawa, T. et al. (2011). Live-Cell Imaging Reveals the Dynamics of Two Sperm Cells during Double Fertilization in Arabidopsis thaliana. Current Biology 21, 497-502.

Harbour, J.W. \& Dean, D.C. (2000). The Rb/E2F pathway: expanding roles and emerging paradigms. Genes \& Development 14, 2393-2409.

Hay, A. \& Tsiantis, M. (2010). KNOX genes: versatile regulators of plant development and diversity. Development 137, 3153-3165.

He, H., Yang, T., Wu, W. \& Zheng, B. (2015). Small RNAs in pollen. Science China Life Sciences 58, 246-252.

Heim, M.A., Jakoby, M., Werber, M., Martin, C., Weisshaar, B. \& Bailey, P.C. (2003). The basic helix-loop-helix transcription factor family in plants: a genome-wide study of protein structure and functional diversity. Molecular biology and evolution 20, 735-747.

Henschel, K., Kofuji, R., Hasebe, M., Saedler, H., Münster, T. \& Theißen, G. (2002). Two Ancient Classes of MIKC-type MADS-box Genes are Present in the Moss Physcomitrella patens. Molecular Biology and Evolution 19, 801-814.

Higo, A., Niwa, M., Yamato, K.T., Yamada, L., Sawada, H., Sakamoto, T. et al. (2016). 
Transcriptional Framework of Male Gametogenesis in the Liverwort Marchantia polymorpha L. Plant and Cell Physiology 57, 325-338.

Hori, K., Maruyama, F., Fujisawa, T., Togashi, T., Yamamoto, N., Seo, M. et al. (2014). Klebsormidium flaccidum genome reveals primary factors for plant terrestrial adaptation. Nature Communications 5, 3978.

Houben, A., Kumke, K., Nagaki, K \& Hause, G. (2011). CENH3 distribution and differential chromatin modifications during pollen development in rye (Secale cereale L.). Chromosome research, 19, 471-480.

Hu, J.H., Yang, N., Ma, Y.H., Jiang, J., Zhang, J.F., Fei, J. et al. (2004). Identification of glutamate receptors and transporters in mouse and human sperm. Journal of Andrology $25,140-146$.

Ikeda, K., Ikeda, T., Morikawa, K. \& Kamiya, R. (2007). Axonemal localization of Chlamydomonas PACRG, a homologue of the human Parkin-coregulated gene product. Cell Motility 64, 814-821.

Ingouff, M., Jullien, P.E. \& Berger, F. (2006). The female gametophyte and the endosperm control cell proliferation and differentiation of the seed coat in Arabidopsis. The Plant Cell 18, 3491-3501.

Ingouff, M., Sakata, T., Li, J., Sprunck, S., Dresselhaus, T. \& Berger, F. (2009). The two male gametes share equal ability to fertilize the egg cell in Arabidopsis thaliana. Current Biology 19, 19-20.

Iwakawa, H., Shinmyo, A. \& Sekine, M. (2006). Arabidopsis CDKA;1, a cdc2 homologue, controls proliferation of generative cells in male gametogenesis. The Plant Journal 45, $819-831$.

Jensen, W.A. \& Fisher, D.B. (1970). Cotton embryogenesis: The pollen tube in the stigma and style. Protoplasma 69, 215-235.

Jiang, H., Yi, J., Boavida, L.C., Chen, Y., Becker, J.D., Kohler, C. et al. (2015). Intercellular communication in Arabidopsis thaliana pollen discovered via $A H G 3$ transcript 
movement from the vegetative cell to sperm. Proceedings of the National Academy of Sciences of the United States of America 112, 13378-13383.

Johnson, G.D., Lalancette, C., Linnemann, A.K., Leduc, F., Boissonneault, G. \& Krawetz, S.A. (2011). The sperm nucleus: chromatin, RNA and the nuclear matrix. Reproduction $141,21-36$.

Johnston, A.J., Matveeva, E., Kirioukhova, O., Grossniklaus, U. \& Gruissem, W. (2008). A Dynamic Reciprocal RBR-PRC2 Regulatory Circuit Controls Arabidopsis Gametophyte Development. Current Biology 18, 1680-1686.

Kaneko, M., Inukai, Y., Ueguchi-Tanaka, M., Itoh, H., Izawa, T., Kobayashi, Y. et al. (2004). Loss-of-function mutations of the rice $G A M Y B$ gene impair alpha-amylase expression in aleurone and flower development. The Plant cell 16, 33-44.

Kaufmann, K., Muiño, J.M., Østerås, M., Farinelli, L., Krajewski, P. \& Angenent, G.C. (2010). Chromatin immunoprecipitation (ChIP) of plant transcription factors followed by sequencing (ChIP-SEQ) or hybridization to whole genome arrays (ChIP-CHIP). Nature Protocols 5, 457.

Keiko, S., Tomoaki, N., Hironori, D. \& Mitsuyasu, H. (2008). Class 1 KNOX genes are not involved in shoot development in the moss Physcomitrella patens but do function in sporophyte development. Evolution \& Development 10, 555-566.

Kim, H.J., Oh, S.A., Brownfield, L., Hong, S.H., Ryu, H., Hwang, I. et al. (2008). Control of plant germline proliferation by SCFFBL17 degradation of cell cycle inhibitors. Nature $455,1134$.

Kim, M., Kim, M.-J., Pandey, S. \& Kim, J. (2016). Expression and Protein Interaction Analyses Reveal Combinatorial Interactions of LBD Transcription Factors During Arabidopsis Pollen Development. Plant and Cell Physiology 57, 2291-2299.

Kim, M., Kim, M., Lee, M.R., Park, S.K. \& Kim, J. (2015). LATERAL ORGAN BOUNDARIES DOMAIN (LBD)10 interacts with SIDECAR POLLEN/LBD27 to control pollen development in Arabidopsis. The Plant Journal 81, 794-809. 
Koi, S., Hisanaga, T., Sato, K., Shimamura, M., Yamato, K.T., Ishizaki, K. et al. (2016). An Evolutionarily Conserved Plant RKD Factor Controls Germ Cell Differentiation. Current Biology 26, 1775-1781.

Kong, J., Lau, S. \& Jurgens, G. (2015). Twin plants from supernumerary egg cells in Arabidopsis. Current biology, 25, 225-230.

Koshimizu, S., Kofuji, R., Sasaki-Sekimoto, Y., Kikkawa, M., Shimojima, M., Ohta, H. et al. (2018). Physcomitrella MADS-box genes regulate water supply and sperm movement for fertilization. Nature Plants 4, 36-45.

Kurusu, T., Koyano, T., Hanamata, S., Kubo, T., Noguchi, Y., Yagi, C. et al. (2014). OsATG7 is required for autophagy-dependent lipid metabolism in rice postmeiotic anther development. Autophagy 10, 878-888.

Kwantes, M., Liebsch, D. \& Verelst, W. (2012). How MIKC* MADS-Box Genes Originated and Evidence for Their Conserved Function Throughout the Evolution of Vascular Plant Gametophytes. Molecular Biology and Evolution 29, 293-302.

Kwiatkowska, M., Kaźmierczak, A. \& Popłońska, K. (2002). Ultrastructural, autoradiographic and electrophoretic examinations of Chara tomentosa spermiogenesis. Acta Societatis Botanicorum Poloniae 71, 201-209.

Lee, J.-H., Lin, H., Joo, S. \& Goodenough, U. (2008). Early Sexual Origins of Homeoprotein Heterodimerization and Evolution of the Plant KNOX/BELL Family. Cell 133, 829-840.

Lee, Y.-R.J., Li, Y. \& Liu, B. (2007). Two Arabidopsis phragmoplast-associated kinesins play a critical role in cytokinesis during male gametogenesis. The Plant Cell 19, 2595-2605.

Lei, R., Li, X., Ma, Z., Lv, Y., Hu, Y. \& Yu, D. (2017). Arabidopsis WRKY2 and WRKY34 transcription factors interact with VQ20 protein to modulate pollen development and function. The Plant Journal 91, 962-976.

Lei, R., Ma, Z. \& Yu, D. (2018). WRKY2/34-VQ20 Modules in Arabidopsis thaliana Negatively Regulate Expression of a Trio of Related MYB Transcription Factors During Pollen Development. Frontiers in Plant Science 9, 331. 
Leydon, A.R., Beale, K.M., Woroniecka, K., Castner, E., Chen, J., Horgan, C. et al. (2013). Three MYB transcription factors control pollen tube differentiation required for sperm release. Current Biology 23, 1209-1214.

Li, L., Wu, W., Zhao, Y. \& Zheng, B. (2017). A reciprocal inhibition between ARID1 and MET1 in male and female gametes in Arabidopsis. Journal of integrative plant biology $59,657-668$.

Li, W., Wu, J., Kim, S.-Y., Zhao, M., Hearn, S.A., Zhang, M.Q. et al. (2014). Chd5 orchestrates chromatin remodelling during sperm development. Nature Communications 5,3812 .

Liang, Y., Tan, Z.-M.M., Zhu, L., Niu, Q.-K.K., Zhou, J.-J.J. \& Li, M. et al. (2013). MYB97, MYB101 and MYB120 Function as Male Factors That Control Pollen Tube-Synergid Interaction in Arabidopsis thaliana Fertilization. PLOS Genetics 9, e1003933.

Ligrone, R., Duckett, J.G. \& Renzaglia, K.S. (2012). Major transitions in the evolution of early land plants: a bryological perspective. Annals of Botany 109, 851-871.

Lin, Q., Ohashi, Y., Kato, M., Tsuge, T., Gu, H., Qu, L.-J. et al. (2015). GLABRA2 Directly Suppresses Basic Helix-Loop-Helix Transcription Factor Genes with Diverse Functions in Root Hair Development. The Plant Cell 27, 2894-2906.

Liu, S.-L. \& Adams, K.L. (2010). Dramatic change in function and expression pattern of a gene duplicated by polyploidy created a paternal effect gene in the Brassicaceae. Molecular Biology and Evolution 27, 2817-2828.

Liu, Y., Cui, S., Wu, F., Yan, S., Lin, X., Du, X. et al. (2013). Functional Conservation of MIKC*-Type MADS Box Genes in Arabidopsis and Rice Pollen Maturation. The Plant Cell 25, 1288-1303.

Liu, Y., Du, L., Osato, M., Teo, E.H., Qian, F., Jin, H. et al. (2007). The zebrafish $u d u$ gene encodes a novel nuclear factor and is essential for primitive erythroid cell development. Blood 110, 99-106.

Lopez-Smith, R. \& Renzaglia, K. (2008). Sperm cell architecture, insemination, and 
fertilization in the model fern, Ceratopteris richardii. Sexual Plant Reproduction 21, $153-167$.

Lora, J., Herrero \& M., Hormaza, J.I. (2009). The coexistence of bicellular and tricellular pollen in Annona cherimola (Annonaceae): Implications for pollen evolution. American journal of Botany 96, 802-808.

Lorenzetti, D., Bishop, C.E. \& Justice, M.J. (2004). Deletion of the Parkin coregulated gene causes male sterility in the quaking(viable) mouse mutant. Proceedings of the National Academy of Sciences of the United States of America 101, 8402-8407.

Lu, P., Hankel, I.L., Hostager, B.S., Swartzendruber, J.A., Friedman, A.D., Brenton, J.L. et al. (2011). The developmental regulator protein Gon41 associates with protein YY1, corepressor Sin3a, and histone deacetylase 1 and mediates transcriptional repression. The Journal of biological chemistry 286, 18311-18319.

Lu, Z., Hofmeister, B.T., Vollmers, C., DuBois, R.M. \& Schmitz, R.J. (2017). Combining ATAC-seq with nuclei sorting for discovery of cis-regulatory regions in plant genomes. Nucleic Acids Research 45, e41-e41.

Martínez, G., Panda, K., Köhler, C. \& Slotkin, R.K. (2016). Silencing in sperm cells is directed by RNA movement from the surrounding nurse cell. Nature Plants 2, 16030.

McCourt, R.M., Delwiche, C.F. \& Karol, K.G. (2004). Charophyte algae and land plant origins. Trends in Ecology \& Evolution 19, 661-666.

McCue, A.D., Cresti, M., Feijo, J.A. \& Slotkin, R.K. (2011). Cytoplasmic connection of sperm cells to the pollen vegetative cell nucleus: potential roles of the male germ unit revisited. Journal of experimental Botany 62, 1621-1631.

Meistrich, M.L., Mohapatra, B., Shirley, C.R. \& Zhao, M. (2003). Roles of transition nuclear proteins in spermiogenesis. Chromosoma $111,483-488$.

Mérai, Z., Chumak, N., García-Aguilar, M., Hsieh, T.-F., Nishimura, T., Schoft, V.K. et al., (2014). The AAA-ATPase molecular chaperone Cdc48/p97 disassembles sumoylated centromeres, decondenses heterochromatin, and activates ribosomal RNA genes. 
Proceedings of the National Academy of Sciences of the United States of America 111, $16166-16171$.

Michard, E., Lima, P.T., Borges, F., Silva, A.C., Portes, M.T., Carvalho, J.E. et al. (2011). Glutamate Receptor-Like Genes Form Ca2+ Channels in Pollen Tubes and Are Regulated by Pistil d-Serine. Science 332, 434-437.

Michard, E., Simon, A.A., Tavares, B., Wudick, M.M. \& Feijó, J.A. (2017). Signaling with Ions: The Keystone for Apical Cell Growth and Morphogenesis in Pollen Tubes. Plant Physiology 173, 91-111.

Mogensen, H.L. (1992). The Male Germ Unit: Concept, Composition, and Significance, in: Russell, S.D., Dumas, C.B.T.-I.R. of C. (Eds.), International Review of Cytology. (pp. 129-147), Academic Press,.

Mori, T., Igawa, T., Tamiya, G., Miyagishima, S. \& Berger, F. (2014). Gamete Attachment Requires GEX2 for Successful Fertilization in Arabidopsis. Current Biology 24, 170175.

Mori, T., Kawai-Toyooka, H., Igawa, T. \& Nozaki, H. (2015). Gamete Dialogs in Green Lineages. Molecular Plant 8, 1442-1454.

Myles, D.G. \& Hepler, P.K. (1977). Spermiogenesis in the fern Marsilea microtubules, nuclear shaping, and cytomorphogenesis. Journal of Cell Science 23, 57-83.

Niklas, K.J. \& Kutschera, U. (2009). The evolution of the land plant life cycle. New Phytologist 185, 27-41.

Norstog, K.J. (1975). The motility of cycad spermatozoids in relation to structure and function, in: Duckett, J.G., Racey, P.A. (Eds.), The Biology of the Male Gamete. (pp. 135-142), Academic Press, London.

Nowack, M.K., Grini, P.E., Jakoby, M.J., Lafos, M., Koncz, C. \& Schnittger, A. (2005). A positive signal from the fertilization of the egg cell sets off endosperm proliferation in angiosperm embryogenesis. Nature Genetics 38, 63.

Nozaki, H., Misawa, K., Kajita, T., Kato, M., Nohara, S. \& Watanabe, M.M. (2000). Origin 
and Evolution of the Colonial Volvocales (Chlorophyceae) as Inferred from Multiple, Chloroplast Gene Sequences. Molecular Phylogenetics and Evolution 17, 256-268.

Oh, S.-A., Bourdon, V., Das 'Pal, M., Dickinson, H. \& Twell, D. (2008). Arabidopsis Kinesins HINKEL and TETRASPORE Act Redundantly to Control Cell Plate Expansion during Cytokinesis in the Male Gametophyte. Molecular Plant 1, 794-799.

Oh, S.A., Allen, T., Kim, G.J., Sidorova, A., Borg, M., Park, S.K. et al. (2012). Arabidopsis Fused kinase and the Kinesin-12 subfamily constitute a signalling module required for phragmoplast expansion. The Plant Journal 72, 308-319.

Oh, S.A., Johnson, A., Smertenko, A., Rahman, D., Park, S.K., Hussey, P.J. et al. (2005). A divergent cellular role for the FUSED kinase family in the plant-specific cytokinetic phragmoplast. Current Biology 15, 2107-2111.

Oh, S.A., Park, K.S., Twell, D. \& Park, S.K. (2010). The SIDECAR POLLEN gene encodes a microspore-specific LOB/AS2 domain protein required for the correct timing and orientation of asymmetric cell division. The Plant Journal 64, 839-850.

Okada, T., Endo, M., Singh, M.B. \& Bhalla, P.L. (2005). Analysis of the histone H3 gene family in Arabidopsis and identification of the male-gamete-specific variant AtMGH3. The Plant Journal 44, 557-568.

Ortiz-Ramírez, C., Michard, E., Simon, A.A., Damineli, D.S.C., Hernández-Coronado, M., Becker, J.D. et al. (2017). GLUTAMATE RECEPTOR-LIKE channels are essential for chemotaxis and reproduction in mosses. Nature 549, 91.

Palatnik, J.F., Wollmann, H., Schommer, C., Schwab, R., Boisbouvier, J., Rodriguez, R. et al. (2007). Sequence and Expression Differences Underlie Functional Specialization of Arabidopsis MicroRNAs miR159 and miR319. Developmental Cell 13, 115-125.

Palevitz, B.A. \& Tiezzi, A. (1992). Organization, Composition, and Function of the Generative Cell and Sperm Cytoskeleton, in: Russell, S.D., Dumas, C.B.T.-I.R. of C. (Eds.), . Academic Press, pp. 149-185.

Pandey, P., Houben, A., Kumlehn, J., Melzer, M. \& Rutten, T. (2013). Chromatin alterations 
during pollen development in Hordeum vulgare. Cytogenetic and genome research 141, $50-57$.

Park, S.K., Howden, R. \& Twell, D. (1998). The Arabidopsis thaliana gametophytic mutation gemini pollen 1 disrupts microspore polarity, division asymmetry and pollen cell fate. Development 125, 3789-3799.

Peters, B., Casey, J., Aidley, J., Zohrab, S., Borg, M., Twell, D. et al. (2017). A Conserved cis-Regulatory Module Determines Germline Fate through Activation of the Transcription Factor DUO1 Promoter. Plant Physiology 173, 280-293.

Petersen, K.B. \& Burd, M. (2016). Why did heterospory evolve? Biological Reviews 92, $1739-1754$.

Proost, S. \& Mutwil, M. (2018). CoNekT: an open-source framework for comparative genomic and transcriptomic network analyses. bioRxiv.

Rathke, C., Barckmann, B., Burkhard, S., Jayaramaiah-Raja, S., Roote, J. \& Renkawitz-Pohl, R. (2010). Distinct functions of Mst77F and protamines in nuclear shaping and chromatin condensation during Drosophila spermiogenesis. European Journal of Cell Biology 89, 326-338.

Renzaglia, K.S. \& Garbary, D.J. (2001). Motile Gametes of Land Plants: Diversity, Development, and Evolution. Critical Reviews in Plant Sciences 20, 107-213. Reynolds, W.F. \& Wolfe, S.L. (1984). Protamines in plant sperm. Experimental Cell Research 152, 443-448.

Reynolds, W.F. \& Wolfe, S.L. (1978). Changes in basic proteins during sperm maturation in a plant, Marchantia polymorpha. Experimental Cell Research 116, 269-273.

Rotman, N., Durbarry, A., Wardle, A., Yang, W.C., Chaboud, A., Faure, J.-E. et al. (2005). A Novel Class of MYB Factors Controls Sperm-Cell Formation in Plants. Current Biology $15,244-248$.

Rövekamp, M., Bowman, J.L. \& Grossniklaus, U. (2016). Marchantia MpRKD Regulates the Gametophyte-Sporophyte Transition by Keeping Egg Cells Quiescent in the Absence of 
Fertilization. Current Biology 26, 1782-1789.

Rowe, N., Paul-Victor, C. \& Paul-Victor, C. (2012). Herbs and secondary woodiness keeping up the cambial habit. New Phytologist 193, 3-5.

Rudall, P.J. \& Bateman, R.M. (2007). Developmental bases for key innovations in the seedplant microgametophyte. Trends in Plant Science 12, 317-326.

Russell, S.D. (1985). Preferential fertilization in Plumbago: Ultrastructural evidence for gamete-level recognition in an angiosperm. Proceedings of the National Academy of Sciences of the United States of America 82, 6129-6132.

Russell, S.D. \& Cass, D.D. (1981). Ultrastructure of the sperms of Plumbago zeylanica. Protoplasma 107, 85-107.

Russell, S.D., Gou, X., Wong, C.E., Wang, X., Yuan, T., Wei, X. et al. (2012). Genomic profiling of rice sperm cell transcripts reveals conserved and distinct elements in the flowering plant male germ lineage. New Phytologist 195, 560-573.

Russell, S.D. \& Jones, D.S. (2015). The male germline of angiosperms: repertoire of an inconspicuous but important cell lineage. Frontiers in Plant Science 6, 173.

Rutley, N. \& Twell, D. (2015). A decade of pollen transcriptomics. Plant Reproduction 28, $73-89$.

Saito, C., Nagata, N., Sakai, A., Mori, K., Kuroiwa, H. \& Kuroiwa, T. (2002). Angiosperm species that produce sperm cell pairs or generative cells with polarized distribution of DNA-containing organelles. Sexual Plant Reproduction 15, 167-178.

Sakakibara, K., Ando, S., Yip, H.K., Tamada, Y., Hiwatashi, Y., Murata, T. et al. (2013). KNOX2 Genes Regulate the Haploid-to-Diploid Morphological Transition in Land Plants. Science 339, 1067-1070.

Sanchez-Vera, V., Kenchappa, C.S., Landberg, K., Bressendorff, S., Schwarzbach, S., Martin, T. et al. (2017). Autophagy is required for gamete differentiation in the moss Physcomitrella patens. Autophagy 13, 1939-1951.

Sano, Y. \& Tanaka, I. (2010). Distinct localization of histone H3 methylation in the 
vegetative nucleus of lily pollen. Cell biology international 34, 253-259.

Santos, M.R., Bispo, C. \& Becker, J.D. (2017). Isolation of Arabidopsis Pollen, Sperm Cells, and Vegetative Nuclei by Fluorescence-Activated Cell Sorting (FACS) in: Schmidt, A. (Ed.) Plant Germline Development: Methods and Protocols. , (pp. 193-210). Springer New York, New York..

Sauter, M., Wiegen, P. von., Lorz, H., Kranz, E., von Wiegen, P., Lörz, H. et al. (1998). Cell cycle regulatory genes from maize are differentially controlled during fertilization and first embryonic cell division, Sexual plant reproduction.

Saze, H. (2008). Epigenetic memory transmission through mitosis and meiosis in plants. Seminars in cell \& developmental biology 19, 527-536.

Saze, H., Mittelsten Scheid, O. \& Paszkowski, J. (2003). Maintenance of CpG methylation is essential for epigenetic inheritance during plant gametogenesis. Nature Genetics 34, 6569.

Schmid, A., Sutto, Z., Nlend, M.-C., Horvath, G., Schmid, N., Buck, J. et al. (2007). Soluble Adenylyl Cyclase Is Localized to Cilia and Contributes to Ciliary Beat Frequency Regulation via Production of cAMP. The Journal of General Physiology 130, 99-109.

Schmidt, A., Schmid, M.W. \& Grossniklaus, U. (2015). Plant germline formation: common concepts and developmental flexibility in sexual and asexual reproduction. Development $142,229-241$.

Schoft, V.K., Chumak, N., Bindics, J., Slusarz, L., Twell, D., Kohler, C. et al. (2015). SYBR Green-activated sorting of Arabidopsis pollen nuclei based on different DNA/RNA content. Plant Reproduction 28, 61-72.

Schoft, V.K., Chumak, N., Mosiolek, M., Slusarz, L., Komnenovic, V., Brownfield, L. et al., (2009). Induction of RNA-directed DNA methylation upon decondensation of constitutive heterochromatin. EMBO Reports 10, 1015-1021.

Sharp, L.W. (1914). Spermatogenesis in Marsilia. Botanical Gazette 58, 419-431.

Shaw, A.J., Szovenyi, P. \& Shaw, B. (2011). Bryophyte diversity and evolution: windows 
into the early evolution of land plants. American journal of Botany 98, 352-369.

Shimamura, M. (2016). Marchantia polymorpha: Taxonomy, Phylogeny and Morphology of a Model System. Plant and Cell Physiology 57, 230-256.

Slotkin, R.K., Vaughn, M., Borges, F., Tanurdžić, M., Becker, J.D., Feijó, J.A. et al. (2009). Epigenetic Reprogramming and Small RNA Silencing of Transposable Elements in Pollen. Cell 136, 461-472.

Snell, R. \& Aarssen, L.W. (2005). Life history traits in selfing versus outcrossing annuals: exploring the "time-limitation" hypothesis for the fitness benefit of self-pollination. BMC Ecology 5, 2.

Southworth, D. \& Cresti, M. (1997). Comparison of Flagellated and Nonflagellated Sperm in Plants. American Journal of Botany 84, 1301-1311.

Soyano, T., Nishihama, R., Morikiyo, K., Ishikawa, M. \& Machida, Y. (2003). NQK1/NtMEK1 is a MAPKK that acts in the NPK1 MAPKKK-mediated MAPK cascade and is required for plant cytokinesis. Genes \& development 17, 1055-1067. Strother, P.K., Al-Hajri, S. \& Traverse, A. (1996). New evidence for land plants from the lower Middle Ordovician of Saudi Arabia. Geology 24, 55-58.

Suzuki, Y., Tsuneya, T., Hori, T., Shogo, K. \& Okada, K. (2000). The Sea in the Seed Sperm of Gingko biloba and Reproductive Evolution in Plants - A scientific video. TokyoCinema, Japan.

Takahashi, T., Honda, K., Mori, T. \& Igawa, T. (2017). Loss of GCS1/HAP2 does not affect the ovule-targeting behavior of pollen tubes. Plant Reproduction 30, 147-152.

Tanabe, Y., Hasebe, M., Sekimoto, H., Nishiyama, T., Kitani, M., Henschel, K. et al. (2005). Characterization of MADS-box genes in charophycean green algae and its implication for the evolution of MADS-box genes. Proceedings of the National Academy of Sciences of the United States of America 102, 2436-2441.

Tanaka, I. \& Ito, M. (1980). Induction of typical cell division in isolated microspores of Lilium longiflorum and Tulipa gesneriana. Plant Science Letters 17, 279-285. 
Terasaka, O. \& Niitsu, T. (1987). Unequal cell division and chromatin differentiation in pollen grain cells - I. Centrifugal, cold and caffeine treatments. The Botanical Magazine Tokyo 100, 205-216.

Tomei, E.J. \& Wolniak, S.M. (2016). Transcriptome analysis reveals a diverse family of kinesins essential for spermatogenesis in the fern Marsilea. Cytoskeleton 73, 145-159.

Tsai, C.W., Van der Weele, C.M. \& Wolniak, S.M. (2004). Differential segregation and modification of mRNA during spermiogenesis in Marsilea vestita. Developmental Biology 269, 319-330.

Tsuji, H., Aya, K., Ueguchi-Tanaka, M., Shimada, Y., Nakazono, M., Watanabe, R. et al., (2006). GAMYB controls different sets of genes and is differentially regulated by microRNA in aleurone cells and anthers. The Plant Journal 47, 427-444.

Twell, D. (2011). Male gametogenesis and germline specification in flowering plants. Sexual Plant Reproduction 24, 149-160.

Twell, D. (1995). Diphtheria toxin-mediated cell ablation in developing pollen: Vegetative cell ablation blocks generative cell migration. Protoplasma 187, 144-154.

Twell, D., Park, S.K., Hawkins, T.J., Schubert, D., Schmidt, R., Smertenko, A. et al., (2002). MOR 1/GEM1 has an essential role in the plant-specific cytokinetic phragmoplast. Nature Cell Biology 4, 711.

Twell, D., Park, S.K. \& Lalanne, E. (1998). Asymmetric division and cell-fate determination in developing pollen. Trends in Plant Science 3, 305-310.

Ueda, K., Kinoshita, Y., Xu, Z.-J., Ide, N., Ono, M., Akahori, Y. et al. (2000). Unusual core histones specifically expressed in male gametic cells of Lilium longiflorum. Chromosoma 108, 491-500.

Ueda, K. \& Tanaka, I. (1994). The basic proteins of male gametic nuclei isolated from pollen grains of Lilium longiflorum. Planta 192, 446-452.

Umen, J.G., 2014. Green Algae and the Origins of Multicellularity in the Plant Kingdom. Cold Spring Harbor Perspectives in Biology 6. 
Verelst, W., Saedler, H. \& Münster, T. (2007a). MIKC* MADS-Protein Complexes Bind Motifs Enriched in the Proximal Region of Late Pollen-Specific Arabidopsis Promoters. Plant Physiology 143, 447-460.

Verelst, W., Twell, D., de Folter, S., Immink, R., Saedler, H. \& Münster, T. (2007b). MADScomplexes regulate transcriptome dynamics during pollen maturation. Genome Biology $8,249$.

von Besser, K., Frank, A.C., Johnson, M.A. \& Preuss, D. (2006). Arabidopsis HAP2 (GCS1) is a sperm-specific gene required for pollen tube guidance and fertilization. Development $133,4761-4769$.

Wallace, S., Fleming, A., Wellman, C.H. \& Beerling, D.J. (2011). Evolutionary development of the plant spore and pollen wall. AoB PLANTS 2011, plr027-plr027.

Weinberg, R.A. (1995). The retinoblastoma protein and cell cycle control. Cell 81, 323-330.

Wellman, C.H. (2010). The invasion of the land by plants: when and where? New Phytologist 188, 306-309.

Whittington, A.T., Vugrek, O., Wei, K.J., Hasenbein, N.G., Sugimoto, K., Rashbrooke, M.C. et al. (2001). MORl is essential for organizing cortical microtubules in plants. Nature $411,610$.

Williams, J.H. (2012). Pollen Tube Growth Rates and the Diversification of Flowering Plant Reproductive Cycles. International Journal of Plant Sciences 173, 649-661.

Williams, J.H. (2008). Novelties of the flowering plant pollen tube underlie diversification of a key life history stage. Proceedings of the National Academy of Sciences of the United States of America 105, 11259-11263.

Williams, J.H., Taylor, M.L. \& O’Meara, B.C. (2014). Repeated evolution of tricellular (and bicellular) pollen. American Journal of Botany 101, 559-571.

Williams, M.L.K., Sawada, A., Budine, T., Yin, C., Gontarz, P. \& Solnica-Krezel, L. (2018). Gon4l regulates notochord boundary formation and cell polarity underlying axis extension by repressing adhesion genes. Nature Communications 9, 1319. 
Wodniok, S., Brinkmann, H., Glöckner, G., Heidel, A.J., Philippe, H., Melkonian, M., et al. (2011). Origin of land plants: Do conjugating green algae hold the key? $B M C$ Evolutionary Biology 11, 104.

Wykes, S.M. \& Krawetz, S.A. (2003). The Structural Organization of Sperm Chromatin. Journal of Biological Chemistry 278, 29471-29477.

Xu, H., Swoboda, I., Bhalla, P.L. \& Singh, M.B. (1999). Male gametic cell-specific expression of H2A and H3 histone genes. Plant Molecular Biology 39, 607-614.

Xue, T., Liu, Z., Dai, X. \& Xiang, F. (2017). Primary root growth in Arabidopsis thaliana is inhibited by the miR159 mediated repression of MYB33, MYB65 and MYB101. Plant Science 262, 182-189.

Yamaoka, S., Nishihama, R., Yoshitake, Y., Ishida, S., Inoue, K., Saito, M. et al. (2018). Generative Cell Specification Requires Transcription Factors Evolutionarily Conserved in Land Plants. Current Biology 28, 479-486.

Yanagimachi, R., Wakayama, T., Kishikawa, H., Fimia, G.M., Monaco, L. \& Sassone-Corsi, P. (2004). Production of fertile offspring from genetically infertile male mice. Proceedings of the National Academy of Sciences of the United States of America 101, $1691-1695$.

Yu, H.-S. \& Russell, S.D. (1992). Male cytoplasmic diminution and male germ unit in young and mature pollen of Cymbidium goeringii: a 3-dimensional and quantitative study. Sexual Plant Reproduction 5, 169-181.

Zhang, J., Huang, Q., Zhong, S., Bleckmann, A., Huang, J., Guo, X. et al. (2017). Sperm cells are passive cargo of the pollen tube in plant fertilization. Nature Plants 3, 17079.

Zhao, X., Harashima, H., Dissmeyer, N., Pusch, S., Weimer, A.K., Bramsiepe, J. et al. (2012). A General G1/S-Phase Cell-Cycle Control Module in the Flowering Plant Arabidopsis thaliana. PLOS Genetics 8.

Zheng, B., Chen, X. \& McCormick, S. (2011). The Anaphase-Promoting Complex Is a Dual Integrator That Regulates Both MicroRNA-Mediated Transcriptional Regulation of 
Cyclin B1 and Degradation of Cyclin B1 during Arabidopsis Male Gametophyte Development. The Plant Cell 23, 1033-1046.

Zheng, B., He, H., Zheng, Y., Wu, W. \& McCormick, S. (2014). An ARID DomainContaining Protein within Nuclear Bodies Is Required for Sperm Cell Formation in Arabidopsis thaliana. PLOS Genetics 10, e1004421.

Zhuang, T., Hess, R.A., Kolla, V., Higashi, M., Raabe, T.D. \& Brodeur, G.M. (2014). CHD5 is required for spermiogenesis and chromatin condensation. Mechanisms of Development $131,35-46$.

Zobell, O., Faigl, W., Saedler, H. \& Münster, T. (2010). MIKC* MADS-Box Proteins: Conserved Regulators of the Gametophytic Generation of Land Plants. Molecular Biology and Evolution 27, 1201-1211. 

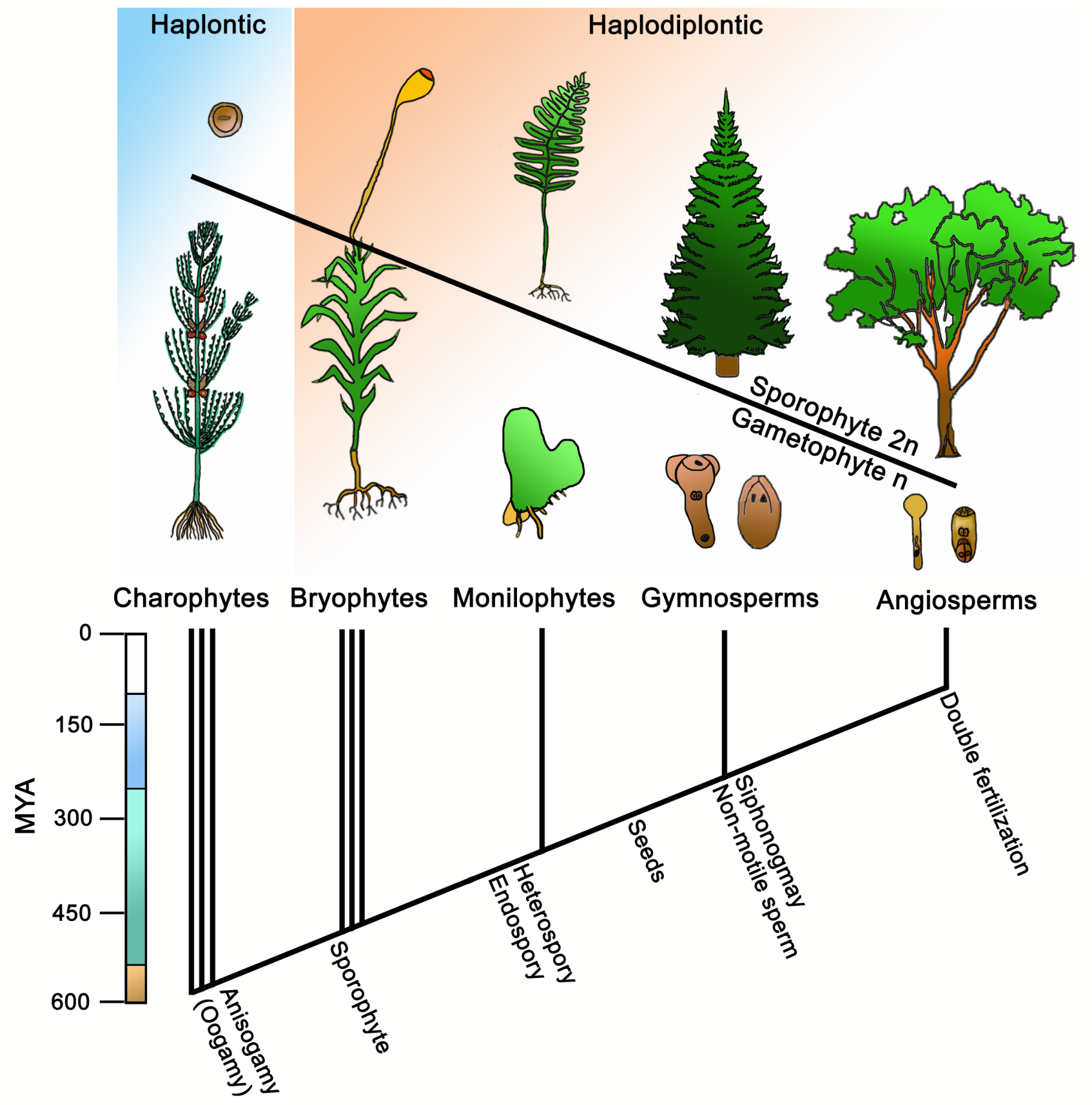
A

B

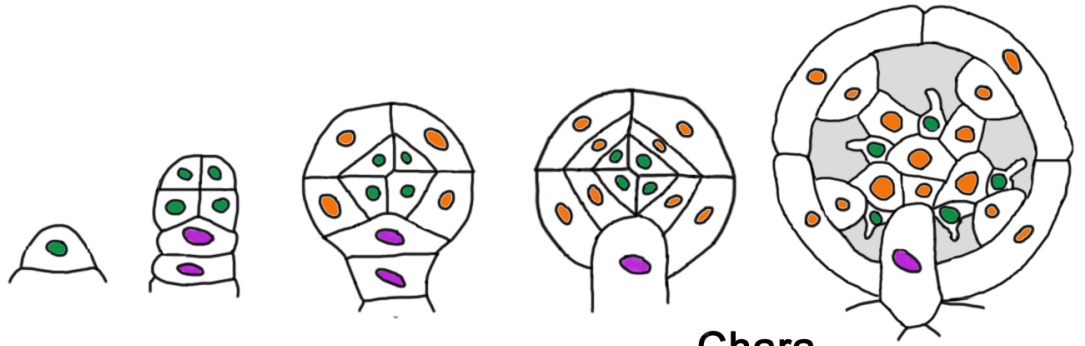

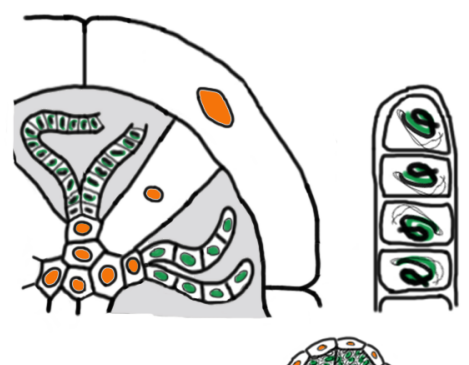

Chara

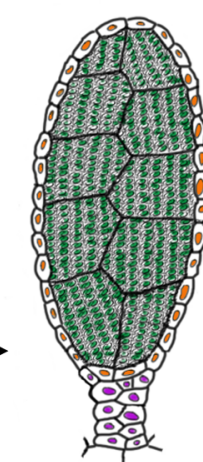

Marchantia

$c$
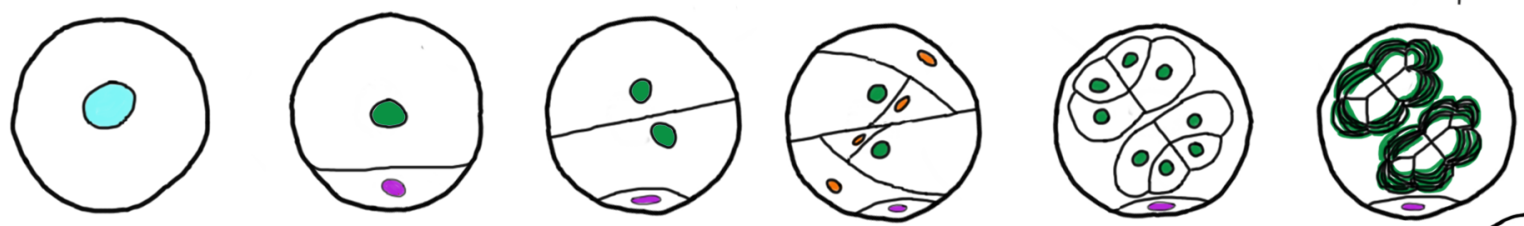

Marsilea

D
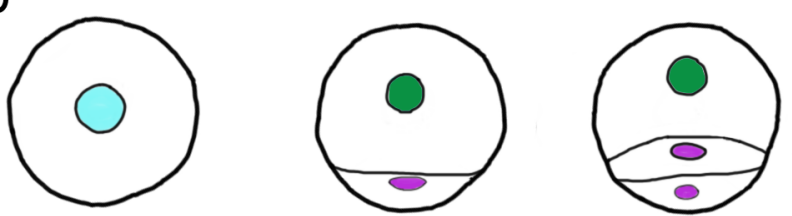

Gingko

E
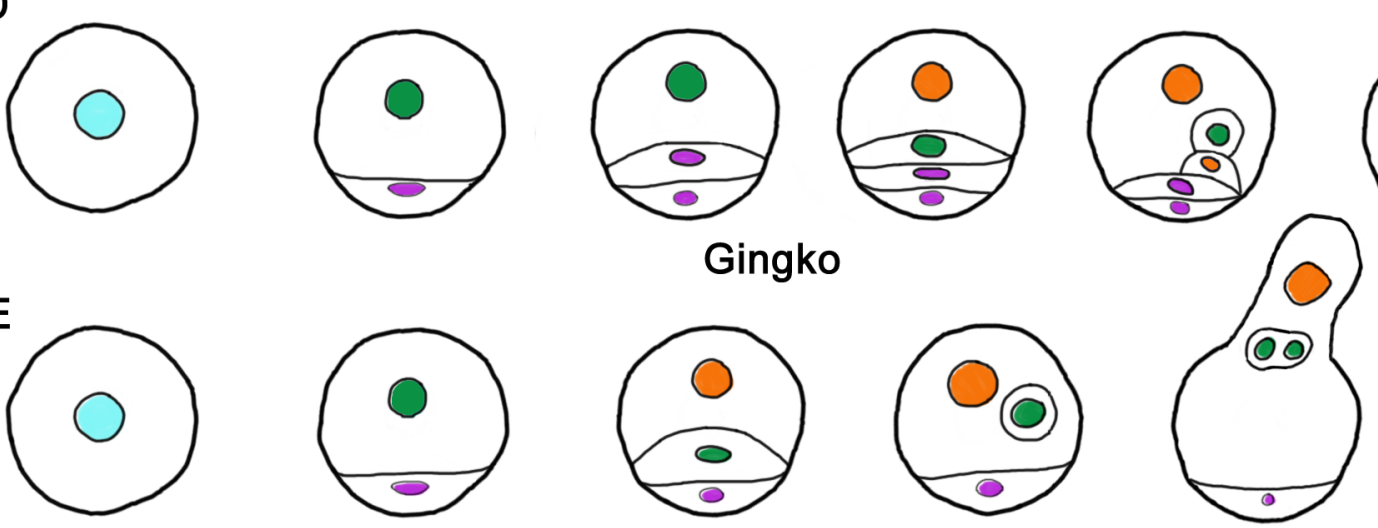

Gnetum

$\mathrm{F}$
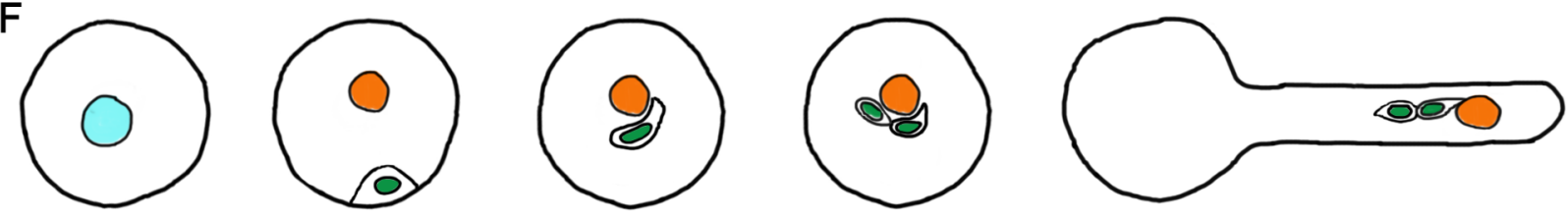

Arabidopsis 
Figure 3

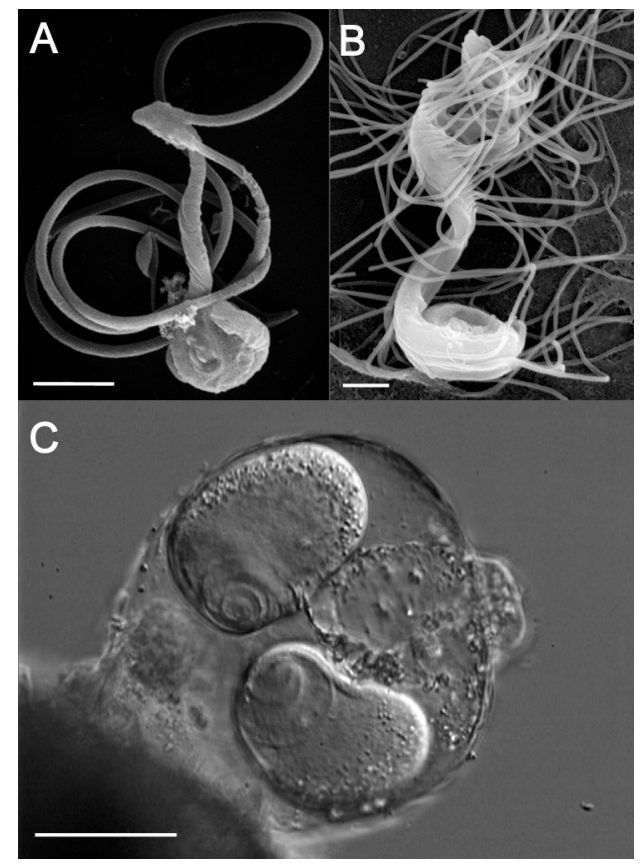


Vegetative cell Generative cell

Sperm cells

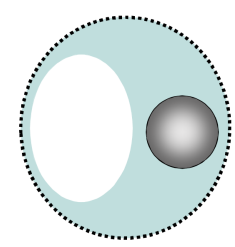

Polarised microspore

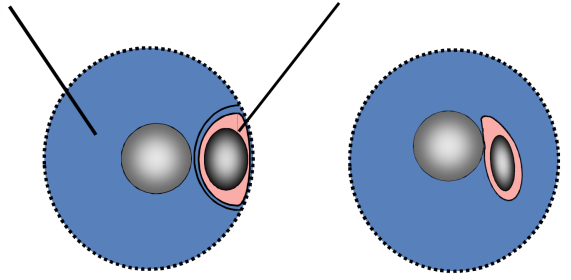

Bicellular pollen

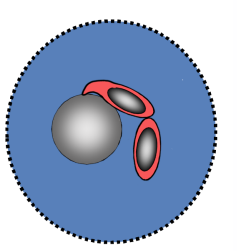

Tricellular pollen

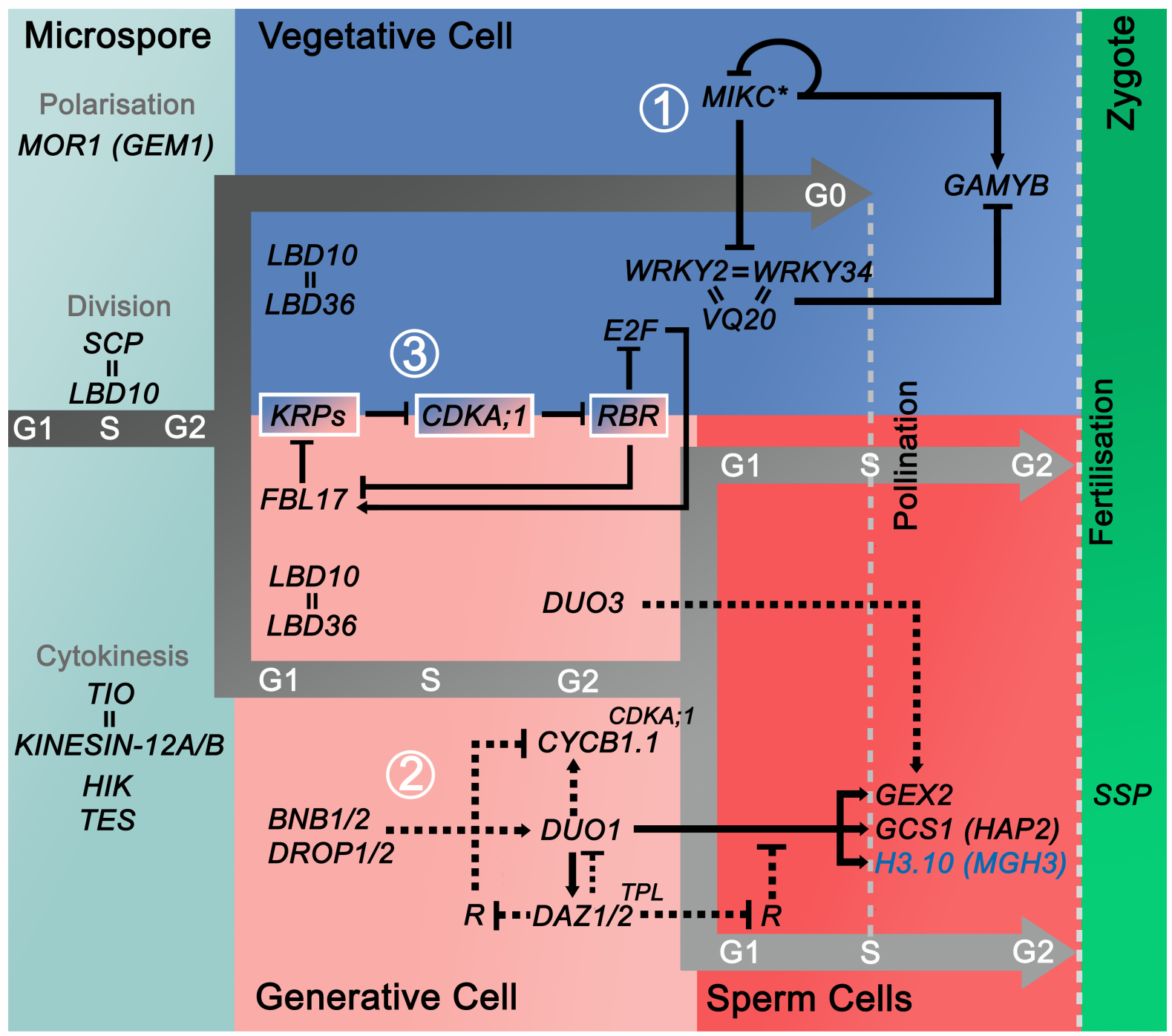

